\title{
WestVirginiaUniversity
}

THE RESEARCH REPOSITORY @ WVU

Graduate Theses, Dissertations, and Problem Reports

2017

\section{Extending the utilization of real time data for pressure transient analysis.}

Jummanh Eyad Aldiwan

Follow this and additional works at: https://researchrepository.wvu.edu/etd

\section{Recommended Citation}

Aldiwan, Jummanh Eyad, "Extending the utilization of real time data for pressure transient analysis." (2017). Graduate Theses, Dissertations, and Problem Reports. 3987.

https://researchrepository.wvu.edu/etd/3987

This Problem/Project Report is protected by copyright and/or related rights. It has been brought to you by the The Research Repository @WVU with permission from the rights-holder(s). You are free to use this Problem/Project Report in any way that is permitted by the copyright and related rights legislation that applies to your use. For other uses you must obtain permission from the rights-holder(s) directly, unless additional rights are indicated by a Creative Commons license in the record and/ or on the work itself. This Problem/Project Report has been accepted for inclusion in WVU Graduate Theses, Dissertations, and Problem Reports collection by an authorized administrator of The Research Repository @ WVU. For more information, please contact researchrepository@mail.wvu.edu. 
Extending the utilization of Real time data for Pressure Transient Analysis

\author{
Jummanh Aldiwan
}

\author{
Problem Report Submitted \\ to the Petroleum and Natural Gas Engineering \\ at West Virginia University
}

In partial fulfillment of the requirements for the degree of

Master of Science in

Department of Petroleum and Natural Gas Engineering

Committee Members:

Kashy Aminian, Ph.D., Chair

Samuel Ameri, Professor

Mehrdad Zamirian, Ph.D.

Department of Petroleum and Natural Gas Engineering

Morgantown, West Virginia

2017

Keywords: Pressure Transient Analysis

Copyright 2017 Jummanh Aldiwan 


\section{ABSTRACT \\ Extending the utilization of Real time data for Pressure Transient Analysis}

\section{Jummanh Aldiwan}

Owing to the gradual fall in prices and the constant increase in reliability of Permanent Down-hole Measurement System (PDHMS), its installation has tremendously grown in number over the recent years.

The advantages of this venture, however, can only be achieved when it is improved to a source for reservoir characterization from mere surveillance and monitoring. This study evaluates workflows and systems that have been installed to change the enormous amounts of data, such as temperature, flow rate and pressure, into practicable information to enhance field performance and development. In addition to using data from real cases from intelligent fields (I-Field) to present a dynamic real-time well testing workflow, this study assesses the Applicability of pressure transient analysis using I-Field real-time information from Permanent Down-hole Gauges to describe well performance and reservoir.

In the study, Multi-Phase Flow Meters (MPFM) and actual real-time PDHMS were explored, I-Field data was applied and investigated to estimate well performance and to establish reservoir parameters. Saphir application was utilized for modeling and analysis and Diamant application was used to filter and control the real-time data. 


\section{TABLE OF CONTENTS}

- INTRODUCTION 4

- CHAPTER 1: LITERATURE REVIEW____________ 6

- CHAPTER 2: MATHEMATICAL AND PHYSICAL BACKGROUND____ 8

2.1 PRESSURE TRANSIENT ANALYSIS_______ 8

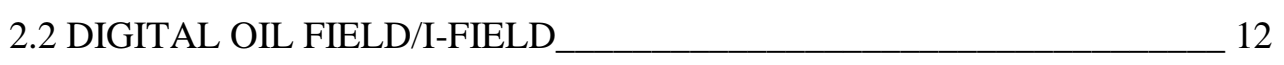

2.3 PERMANENT DOWNHOLE MEASUREMENT SYSTEMS______ 13

2.4 WAVELET FILTRATION____ 15

2.5 KAPPA SOFTWARE (SAPHIR) __ 20

- CHAPTER 3: DYNAMIC PRESSURE TRANSIENT ANALYSIS WORKFLOW___ 23

3.1 DATA COLLECTION________________ 23

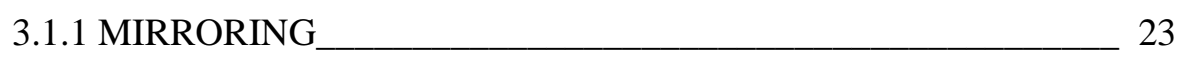

3.1.2 DATA REDUCTION___ 24

3.1.3 DATA QUALITY CONTROL____ 25

3.2. DATA ANALYSIS AND INTERPRETATION____ 26

3.3. RESULTS____ 29

- CHAPTER 4: CASE DESCRIPTIONS______ 30

4.1 CASE (1) ___ 30

4.1.1 DATA COLLECTION___ 30

4.1.2 DATA ANALYSIS AND INTERPRETATION__ 33

4.1.3 RESULTS___________ 34

4.2 CASE (2) ___ 37

4.2.1 DATA COLLECTION____ 37

4.2.2 DATA ANALYSIS AND INTERPRETATION____

4.2.3 RESULTS_____________ 41

- CONCLUSION____ 43

- REFERENCES___ 44 


\section{LIST OF TABLES}

- TABLE (1): DATA MEASUREMENT POINT_______ 9

- TABLE (2): WELL TEST OBJECTIVE_____ 11

- TABLE (3): EQUATIONS OF DATA ANALYSIS___ 28 


\section{LIST OF FIGURES}

- FIGURE 1: SIMPLEST EXAMPLE OF SCALING AND WAVELET FUNCTIONS

- FIGURE 2: SCHEMATIC OF A SINGLE-FREQUENCY WAVELET ALGORITHM

- FIGURE 3: SCHEMATIC OF COMPLETE WAVELET ALGORITHM

- FIGURE 4: REAL SCALING AND WAVELET FUNCTIONS

- FIGURE 5: SAPHIR WORKFLOW

- FIGURE 6: ANALYSIS PLOT

- FIGURE 7: NUMERICAL MODEL

- FIGURE 8: EXAMPLE OF PDHMS DATA NOISE AND OUTLIER REMOVAL USING WAVELET ALGORITHM

- FIGURE 9: MULTIPLE PRESSURE BUILDUP ANALYSIS USING PDHMS DATA

- FIGURE 10: WELL PARAMETERS

- FIGURE 11: RESERVOIR PARAMETERS

- FIGURE 12: FORMATION ANALYSIS LOGS FOR CASE 1

- FIGURE 13: CASE 1 DATA

- FIGURE 14: CASE 1 MODELED DATA

- FIGURE 15: LOG-LOG ANALYSIS OF THE LAST BUILDUP FOR CASE 1

- FIGURE 16: SEMILOG ANALYSIS OF THE LAST BUILDUP FOR CASE 1

- FIGURE 17: CASE 2 FORMATION ANALYSIS LOGS

- FIGURE 18: CASE 2 WELL CROSS SECTION

- FIGURE 19: CASE 2 DATA

- FIGURE 20: PRE-ACID LOG-LOG ANALYSIS FOR CASE 2

- FIGURE 21: POST-ACID LOG-LOG ANALYSIS FOR CASE 2 


\section{INTRODUCTION}

Many major oil companies have invested in acquiring real-time data from their fields for a long time. Permanent downhole measurement systems (PDHMS) are becoming an important part of latest intelligent fields (I-Field) development plans. Permanent Downhole Measurement Systems (PDHMS) became the main source of information in capturing real-time reservoir pressure response due to the extensive adaptation of the I-Field. In the years to come, further investment toward these approaches is anticipated. The definite real-time data collected using these systems are not utilized completely. Worldwide, PDHMS installations is dated back to the 1960s, when they were mostly applied in operational rationale such as to monitor downhole equipment and pumps. PDHMS installations on the other hand were not very familiar up to the untimely 1990s, their value spread more widely since the dependability of PDHMS installations expanded.

The main advantages of this application however, can be recognized only when it is taken from examination and simple surveillance to a source for characterization of reservoir. Workflows and systems should be developed for the transformation of the large amounts of data, flow rate, temperature and pressure, into actionable information for the enhancement of field performance and development.

PDHMS together with Multi-Phase Flow Meters (MPFM) is also capable of providing for more value through the translation of their data into reservoir characterization information. Well shutdown and occasional field will lead to build-ups that may be known as 'free well tests' that can be used in provision of crucial information concerning the field, well performance and evolution through time. Established workflow is necessary in managing the real-time data when it comes to filtering, denoising, retrieval and storage is necessary in attaining the maximum advantage of the instrumentation investments.

This study will build up utilization cases for the use of permanent downhole pressure gauges for describing reservoir and evaluating performance with pressure transient analysis. Multi-Phase Flow Meters (MPFM) data and actual real-time PDHMS will be applied in this study. Reservoir, field and well data will be assessed and validated. These data will then be analyzed to evaluate well performance and find out reservoir parameters. 
This study will mainly deal with the analysis and evaluation of these data to illustrate well performance and reservoir evolution.

The objective of this study is to develop a dynamic real-time well testing workflow, with the use of data from the intelligent fields. The study will present a methodology for pressure transient analysis with the use of I-Field real-time data from Permanent Downhole Gauges. In addition, data quality issues as well as the benefits of the developed workflow will be discussed. 


\section{CHAPTER 1: LITERATURE REVIEW}

The first paper to discuss the use of permanently installed bottomhole pressure gauges is by W.A. Nestlerode (1963). Nestlerode identified potential operation problems for obtaining the necessary reservoir data for effective control. More recent literature is summarized in the following paragraphs.

Athichanagorn et al. (1999) present a methodology and sequential steps for analysis of the data acquired with permanent downhole pressure gauges. A variety of wavelet algorithms are discussed to denoise the data and provide reliable pressure transient trend.

Ortiz et al. (2009) tested several wavelet denoising techniques on a large volume of PDHMS data. The effect of wavelet type, threshold, and resolution level, were discussed. The paper classified and rated each technique for comparison.

Chorneyko (2006) presented the operational aspects of permanent downhole pressure gauges and practical cases of information obtained and reservoir management decisions derived from the PDHMS. The author also highlighted the ever-increasing number of gauge installations across the industry. The author stressed the fact that such a sizeable investment required active stewardship to realize effective utilization.

De Oliveira Silva and Kato (2004) presented a successful case of utilizing PDHMS data to identify barrier and inter-reservoir connectivity, which eliminated the need for workovers or survey services. This paper illustrated how PDHMS can be a vital tool to achieve sound reservoir management, completion, and production decisions.

Horne (2007) discussed methods and algorithms to manage and interpret permanent downhole pressure gauge data for the industry to make the best use of this source of the bundant data. The author highlighted the need to store the PDHMS data in a manner that allows efficient access and recovery. Also, the author stressed that the problems were not yet fully solved, and research in this area is needed to develop a set of reliable automated algorithms to gain maximum advantage.

Suzuki and Chorneyko (2009) presented a new method for automatic pressure buildup detection from PDHMS. This method analyzes the pressure response for specific patterns and the change of pressure over a specific time window to identify the start of the buildup or drawdown periods. The authors tested this method on field cases with positive results. 
Fuyong Wang and Shiyi Zheng (2014) this paper describe a new method of analyzing long-term Permanent Down-hole Gauge (PDG) data for real-time reservoir monitoring. The wavelet frequency analysis approach developed can identify dynamic changes in reservoir properties and well conditions from PDG data.

Chuan Tian and Roland N. Horne (2015) presented the permanent downhole gauges (PDGs) provide a continuous record of pressure, temperature, and sometimes flow rate during well production. The continuous record provides us rich information about the reservoir and makes PDG data a valuable source for reservoir analysis.

In summary, the information in the literature is focused on PDHMS data denoising, filtration, and events detection. There are very limited publications on the utilization of the collected data in reservoir characterization and well performance evaluation, which is the focus of this study. 


\section{CHAPTER 2: MATHEMATICAL AND PHYSICAL BACKGROUND}

Technical information is presented in simplified and abstracted forms so as to give wide knowledge and a general perspective on topics directly connected to this study.

\subsection{Pressure Transient Analysis}

From the first drill-stem test run in 1926, pressure transient analysis (PTA) or well testing has steadily improved. The well testing has transformed from a primitive compound packer and valve run on drill-string into an expansive array of complex downhole and surface technologies, All oil companies are interested in knowing the nature of fluids, the flow rates, and the duration of the sustainable production.

A number of answers to such important questions can be provided by well testing, given the correct technology, planning, and implementation. Generally, well testing has been useful in determining completion efficiency, productivity index, formation damage, production capacity, vertical layering, formation heterogeneities, drawdown pressures, flow rates, permeability, fluid properties, areal extent, distance to boundaries, reservoir pressures, etc.

The testing process involves the determination of in-situ reservoir conditions and fluids as they flow from the structure revealing a range of dynamic and sometimes exceptional dimensions. In accordance with the level of a test, several parameters are determined at many points along the flow path, enabling engineers to evaluate flow rates, temperatures, and down-hole pressures against surface measurements (Table 1). Operators apply well testing to obtain reservoir fluid samples, both at the surface and down-hole, to examine modifications in fluid composition and properties between the wellhead and the perforation. This data is essential in predicting the future characteristics of a well or a reservoir completion. 


\section{TABLE 1: DATA MEASUREMENT POINT}

\begin{tabular}{|l|l|}
\hline Wellhead & Pressure, Temperature and Rate (if equipped with flow meter) \\
\hline Choke manifold & Pressure and Temperature \\
\hline Downhole recording & Pressure and Temperature \\
\hline Wireline tools & $\begin{array}{l}\text { Pressure, Temperature, Flow rate and Sample across single or multiple } \\
\text { depth portfolios }\end{array}$ \\
\hline Separator & $\begin{array}{l}\text { Pressure, Temperature, Rate (oil, water and gas), Shrinkage factors, } \\
\text { Specific gravities (Oil and gas) and fluid samples. }\end{array}$ \\
\hline
\end{tabular}

A well test, in its most fundamental form, marks the changes in downhole pressure that succeeds a change in flow rate. Often, samples of produced fluids, surface flow rates, down-hole pressures and temperatures are obtained.

Well testing by means of PTA objectives modifies with each phase in the life of a well and the reservoir. In the course of the appraisal and exploration phase, well testing assists in the determination of the reservoir size, its permeability and fluid properties. Together with the rates of production and pressures, this information is useful in assessing the commercial viability and deliverability of a prospect, and it is significant for setting aside reserves. Of basic importance in the initial stages of a prospect's assessment are the characteristics of fluid. These characteristics help Oil companies when determining suitable process apparatus to be used in treating and moving extracted fluids from the well to the refinery plant. In the process, the attention moves from evaluating fluid characteristics and deliverability to assessing flow and pressure and establishing compartmentalization inside the reservoir.

These facts are necessary in processing the field development plan and optimize situation of successive wells. Well tests, at the production stage, are performed to appraise completion effectiveness and analyze unanticipated alteration in production. Whether production rejects are brought about by the completion or by the reservoir can be determined by these tests.

These results, in the later times of the reservoir, will be essential for evaluating succeeding secondary recovery plans. 
Generally, PTA for well testing can be categorized as either descriptive or productivity tests. Descriptive tests are necessary in the determination of reservoir boundaries, analysis of vertical and horizontal permeability and estimation of a reservoir's volume and flow rates. Conversely, productivity tests are conducted to find relevant samples of reservoir fluids and to verify fluid-flow rate at particular reservoir static and active pressure (Table 2). Productivity testing is characteristically aimed at obtaining stable bottomhole pressures over many unique flow capacities. After bottomhole pressures and temperatures have been proved stable through continual measurements, consecutive rate changes are achieved by adjusting choke size.

Descriptive tests, unlike testing to get stabilized bottomhole assessment, necessitate transient pressure assessments. Transient pressures are stimulated by step adjustments in surface production capacities and can be estimated by permanent downhole pressure gauges or a bottomhole pressure sensor. Continuous alterations in production lead to pressure agitations that arise from the wellbore to the adjacent developments.

The geological features and fluids inside the reservoir affect these pressure pulsations. Even as they may move directly through a standardized pattern, low-permeability zones may hinder these pulses or may completely disappear when they go into a gas cap. The operator, by measuring wellbore pressure response over time, could get a pressure curve that is determined by the specific fluids contained in the reservoir and the geometry of geological aspects. 
TABLE 2: WELL TEST OBJECTIVE

\begin{tabular}{|l|}
\hline Productivity Tests \\
\hline Obtain and analyze representative sample of produced fluids \\
\hline Measure reservoir pressure and temperature \\
\hline Determine inflow performance relationship and deliverability \\
\hline Evaluate completion efficiency \\
\hline Characterize well damage \\
\hline Evaluate workover or stimulation treatments \\
\hline Descriptive Tests \\
\hline Evaluate reservoir parameters \\
\hline Characterize reservoir heterogeneities \\
\hline Assess reservoir extent and geometry \\
\hline Evaluate hydraulic communication between wells \\
\hline
\end{tabular}

To enable for efficient determination of a reservoir, the characteristics of reservoir fluids and their contacts with production systems, completion and reservoir rock have to be carefully classified. This classification is achieved by means of reservoir modeling, while well test information gives a power for carrying out model simulations. Petrophysical data, geological, and geophysical provide a framework for developing reservoir models. Active well test information's are included into this fixed framework to predict and simulate reservoir characteristics. PTA data are mostly helpful in sensing gradients, fluid contacts, fractures, structural boundaries, permeability barriers and heterogeneities that can be integrated into the model.

A reservoir model, once it is built, is calibrated by evaluating test simulation results against calculated data to verify its parameters. For the purpose of achieving a good match between modeled and real data, the operator needs to tune some assumptions in the model about the well and its reservoir, including distance to a fault, permeability, and other parameters. 
In this field, Production histories from wells are then entered into the replica. Another simulation is performed across the reservoir and to model pressures at the wellbore. Wellbore pressures and simulationderived fluid ratio are impaled via a history-matching process to compare them with measured production pressures and ratios. It is common for initial results to differ, whereby the model parameters are also altered. This iterative procedure persists until a good match is acquired between simulated and actual results. In that case, reservoir model can be applied in prediction of completion scenarios, future production and well location.

One of the most helpful applications of well test information is perhaps accomplished via PTA. Analysts could observe pressure changes in detail through generation of a log-log plot of calculated pressure over time, when plotted together with the derivative of varying pressure. The pressure change derivative gives a typical mark of reservoir pressure reaction to well testing that can be construed based on reservoir volumes, heterogeneities, formation damage, permeability, boundaries and flow regimes. When incorporated into these and other complex interpretation methods, PTA data assists production teams to appreciate their reservoirs and attain their business and engineering objectives.

\subsection{Digital Oil Field/I-Field}

The oil industry has a lengthy account of utilizing the accelerating supremacy of digital technology. The growing performance of digital devices like bandwidth, processors and storage is resulting in waves of technological modernization that guarantee momentous latest qualifications for Oil firms. Consequently, the industry remains at the peak of the digital oil field of the future (DOFF). This will give room for field workers and petro- professionals to gain from full asset understanding of their capability of monitoring and managing all equipped activities in real time, in spite of the site.

It is understood that this state-of-the-art technology for developing, producing and finding oil and gas will probably play a very significant task in giving room the Oil companies to recognize the full economic prospective of their skill.

Below are the main advantages presented by the DOFF:

a) Improved recovery: The DOFF is capable of providing improved data, enhance decisions, and improve implementation in operations and production planning, resulting in extra hydrocarbon recovery. 
b) Lower operating costs: Revamped work processes, labor-saving automation, operations practices and more efficient maintenance-all DOFF-related-result in greater equipped competence. Companies could recognize in service savings of billions extent for every year.

c) Increased production rates: Improving well management and reducing equipment failures raises production volumes, with debottlenecking and optimization efforts offering more benefits. Currently, the industry maneuvers at 80 to 90 percent of its technical competence. The DOFF could increase this utilization rate by 2 up to 6 percent.

d) Diminution in capital costs: The DOFF notion stands for the next step in a migration toward the use of computing systems to control and monitor remote machinery.

These benefits do not exist independent of one another. Instead they depend on a strong interdependence in order to accomplish their utmost gains. The technologies and processes that enable greater production volumes also control water and gas handling, powerfully manipulating ultimate recovery capacities. Exploiting and discovering further reserves boost facility all through and the call for optimization.

DOFF benefits will not turn up simply by obtaining more and better data from all facets of gas and oil operations. Organizational changes and transformative work processes will possibly be required to make use of the latest technologies, one of which is the exploitation of real-time data from PDHMSs into the PTA process and well testing.

\subsection{Permanent Downhole Measurement Systems}

For the past one hundred years, petroleum development and exploration has advanced from simple techniques, like digging a hole into a supposed reservoir, to complex production control and monitoring techniques. Since then, the petroleum industry has developed into a multibillion-dollar industry. Since the reserves have become more difficult to find, development and exploration methods have become increasingly intricate.

The need for accurate down hole data is now a requirement for booming reservoir monitoring and production since the petroleum reservoirs accessible nowadays are located in environments that cause loads of technical difficulties in development. Nowadays, petroleum is found in offshore environments, and those established on land also necessitate enhanced oil recovery methods in order to take full advantage of productivity. 
The successful application of enhanced recovery techniques like hydraulic fracturing, water flooding and vertical lift performance, accurate downhole data are necessary.

Permanent sensors and monitoring systems assist in guaranteeing optimization of production methods and reservoir monitoring by providing the petroleum engineer with real-time data to make accurate and timely decisions. A case in point is whether to acidize a well or fracture it, where to place perforations and how best to conduct a water flood. Data acquired through permanent monitoring systems also gives room for the petroleum engineer to make out tribulations like leaking valves and plugged chokes.

This is the reason behind the study of sensors and permanent monitoring systems. Loads of research is underway in the area of sensors to make them more effective and advance them. Permanent monitoring systems have turned out to be a very significant feature of petroleum technology.

The necessity of accurate down-hole data first resulted in the utilization of surface gauges. It was soon found out that the data obtained with surface gauges was not adequately accurate for oil recovery methods. Wire line gauges were made up for the acquisition of accurate data. This resulted in further inventions, for example the down hole gauge, from which the permanent monitoring system developed.

Permanent sensors are measuring tools that make measurements by showing alterations in properties in reaction to a measured variable like temperature, pressure and flow rate. They are tools that could be mechanical, in the form of an optical fiber or electrical. Sensors are applied in measuring physical variables down hole in the petroleum industry. Examples of measured variables are pressure, electrical resistivity, temperature, flow rate, viscosity and density.

Permanent monitoring systems are capable of greatly improving the decisions made during reservoir development and oil production. Traditional reservoir monitoring techniques however, cannot be cancelled completely. They can be instead used in concurrence with permanent well monitoring systems to enhance the evaluation of the system's accuracy. A problem with the monitoring system can then be detected with ease.

Permanent well monitoring systems are quick in acquiring information as compared with conventional methods of data acquisition. When measurements are being made, information is conveyed via a variety of means of telecommunication for instance satellite communication. Information can get to the petroleum engineer who is answerable to the interpretation of the data in valid time.

Permanent well monitoring systems have advanced from mere data collectors through technology. 
With the latest introduction of a variety of software for interpretation and communication, a well monitoring system is now capable of collecting and interpreting data. In several cases, it may take the necessary action needed in controlling the well, for instance to close a valve with less human intervention. When a permanent well monitoring system is able to take specific actions like the shutting-in of a gas lift valve founded on the data collected by the system without human contribution, is called an intelligent completion.

The intelligent system is a well monitoring system that somewhat has a capacity of managing field production with or without human intervention. It makes the most of field production through the investigation of the data collected with permanent sensors on an unremitting basis. The intelligent completion is intended to last all through the life of the well. In reality however, 55 percent of most downhole electronic sensors record failures in not more than four years.

In order to achieve this form of automated field management, a feedback loop links subsurface controls to the well monitoring system. When the data are being collected, they are interpreted, and the obligatory action is undertaken devoid of a costly work over. Due to the permanent monitoring systems and the high cost of intelligent completions generally, offshore wells only frequently validate such an expense as a result of well interventions for such wells exceed the cost of an intelligent completion to a great extent. Additionally high production rates from offshore wells have the same conditions. Additional wells that apply intelligent completion technology are high-rate production land wells in inaccessible areas. Once more, this is due to the fact that a work over operation in those wells will be more costly than an intelligent completion, and thus makes an intelligent completion an economic choice. The capability of monitoring down-hole variables in real time gives room for a better picture of what really happens in down hole. Besides, the wealth of data collected is to a great extent larger than the data collected with the use of techniques that are more traditional. All these factors assist in producing or engineering reservoir to make efficient decisions in developing or producing reservoir.

\subsection{Wavelet Filtration}

Implementing a smart filter that would considerably cut on the number of data points while maintaining both high and low-frequency data remains the greatest test in the analysis of permanent gauge data. Permanent gauge data obviously make noise. In the production period, for the low-frequency data, some denoising is necessary before the reduction in some points to facilitate an effective reduction. This is the characteristic function of a low-pass filter. Keeping the high- frequency data, however, is the main problem. A low-pass filter masking of a break in the pressure response is not wanted after a shut-in. But we are interested in a high-pass filter at the time of the shut-in. 
Depending on the section of the data we are want, therefore, we are either interested in a high-pass filter or a low-pass filter. Although it acts as a low-pass filter in someplace so as to smooth production stage responses and facilitate an effective data reduction, the solution would be a filter that detects the appropriate break of high-frequency data and operates as a high-pass filter on these breaks to maintain their intact status.

This ought to be conducted with respect to the pressure data, with no knowledge of the well production history a priori. The wavelet algorithms effectively met this specification. It functions as a filter with a threshold for the operator. A particular level is set, below which any noise is taken as noise and is eliminated. Hopefully, most noisy signals during the producing stage falls under this category. In contrast, any noise above the designated threshold level will be taken as a representative break in the data and will be adopted. Whenever the well is shut in, this will hopefully be the case. The break in the pressure information will serve as local and high-level noise.

Wavelet algorithms are multi frequency processes. We will start by showing what happens on a given frequency, corresponding to a time period "a." We use two basic tools: a normalized scaling function ø, used to define a low-pass filter, and a corresponding wavelet function $\psi$, used to define a high-pass filter. These functions must respect the following conditions:

$$
\begin{aligned}
& \int_{-\infty}^{\infty} \emptyset(x) d x=1 \\
& \int_{-\infty}^{\infty} \psi(x) d x=0
\end{aligned}
$$

A simple example for functions $\varnothing$ and $\psi$ is shown in Figure.1.
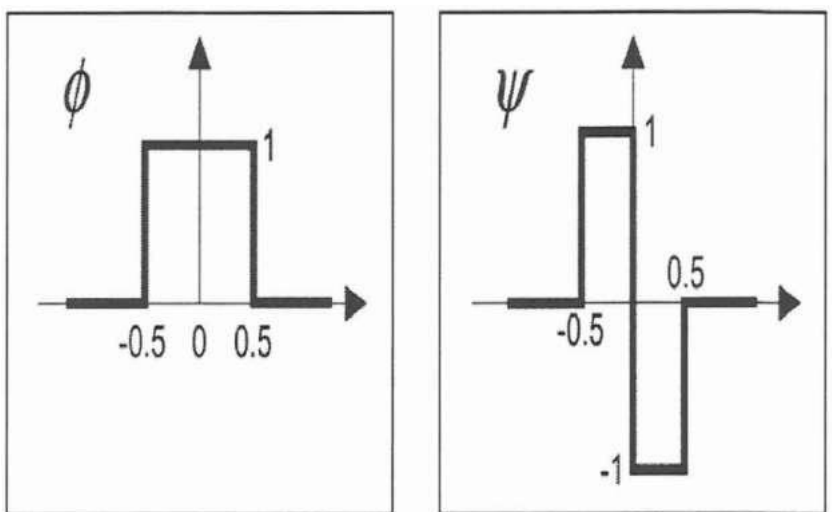

FIGURE1: SIMPLE EXAMPLE OF SCALING AND WAVELET FUNCTIONS 
These functions are used to decompose a given signal (our original data or some transformed data) into two component signals: the complementary transform $\mathrm{C}_{\mathrm{a}}$ and the wavelet transform $\mathrm{W}_{\mathrm{a}}$, by respective convolution of the original data with the scaling and wavelet functions.

$$
\begin{aligned}
& C_{a}(t)=\frac{1}{a} \int_{-\infty}^{\infty} f(x) \emptyset\left(\frac{x-t}{a}\right) d x \\
& W_{a}(t)=\frac{1}{a} \int_{-\infty}^{\infty} f(x) \psi\left(\frac{x-t}{a}\right) d x
\end{aligned}
$$

One remarkable property of these transforms is that there is a numerical way to make these transformations reversible. If we decompose a signal into a wavelet transform and a complementary transform, we will be able to recreate the original signal from these two transforms by a reverse operation.

So these dual transforms act as a projection of the signal into two complementary spaces. This is only possible because the operators and have been carefully chosen. One operator will correspond to one operator, and vice versa.

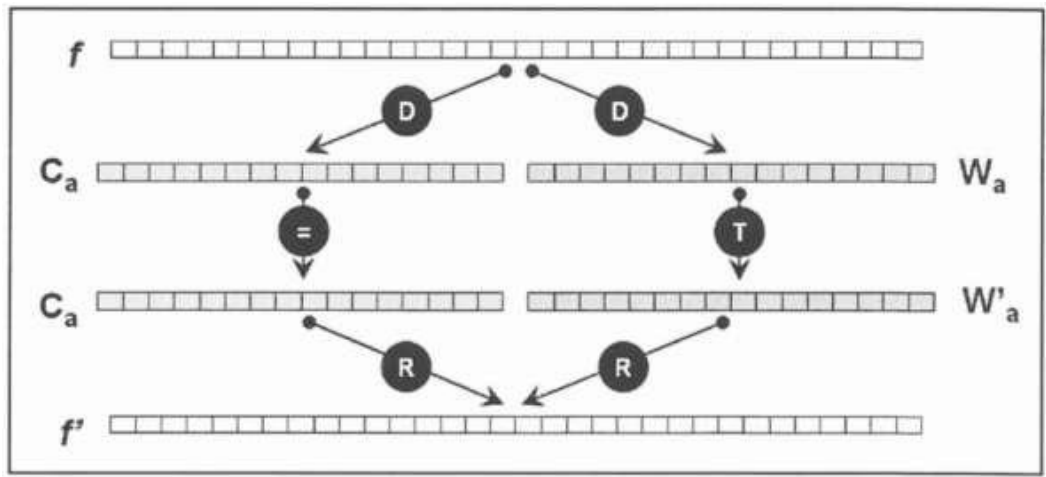

FIGURE 2: SCHEMATIC OF A SINGLE-FREQUENCY WAVELET ALGORITHM:

$$
\text { D = DECOMPOSITION, } T=\text { THRESHOLD, } R=\text { RECOMBINATION }
$$

Comprehensive wavelet denoising is a multiple-frequency process, as shown in Figure 3. In this example, there are four such frequencies. This is a parameter that will be controlled in the filtering application. The process must first interpolate the raw data to start with a set of points with a uniform time spacing a. 


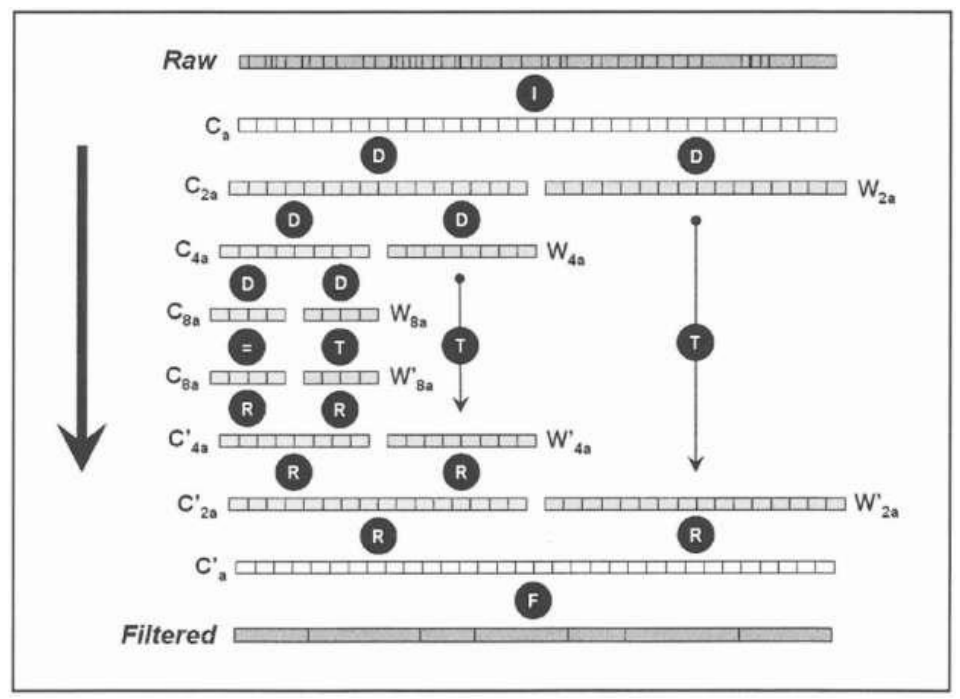

FIGURE 3: SCHEMATIC OF COMPLETE WAVELET ALGORITHM: I = INTERPOLATION, $\mathrm{D}=$ DECOMPOSITION, $\mathrm{T}=$ THRESHOLD, $\mathrm{R}=$ RECOMBINATION, $\mathrm{F}=$ POST - FILTRATION

The functions and $\psi$ presented in Figure 1 are the simplest case. However, functions used on real data are smoother in order to avoid numerical effects. Figure 4 shows another set of functions, more likely to be used on the real data.
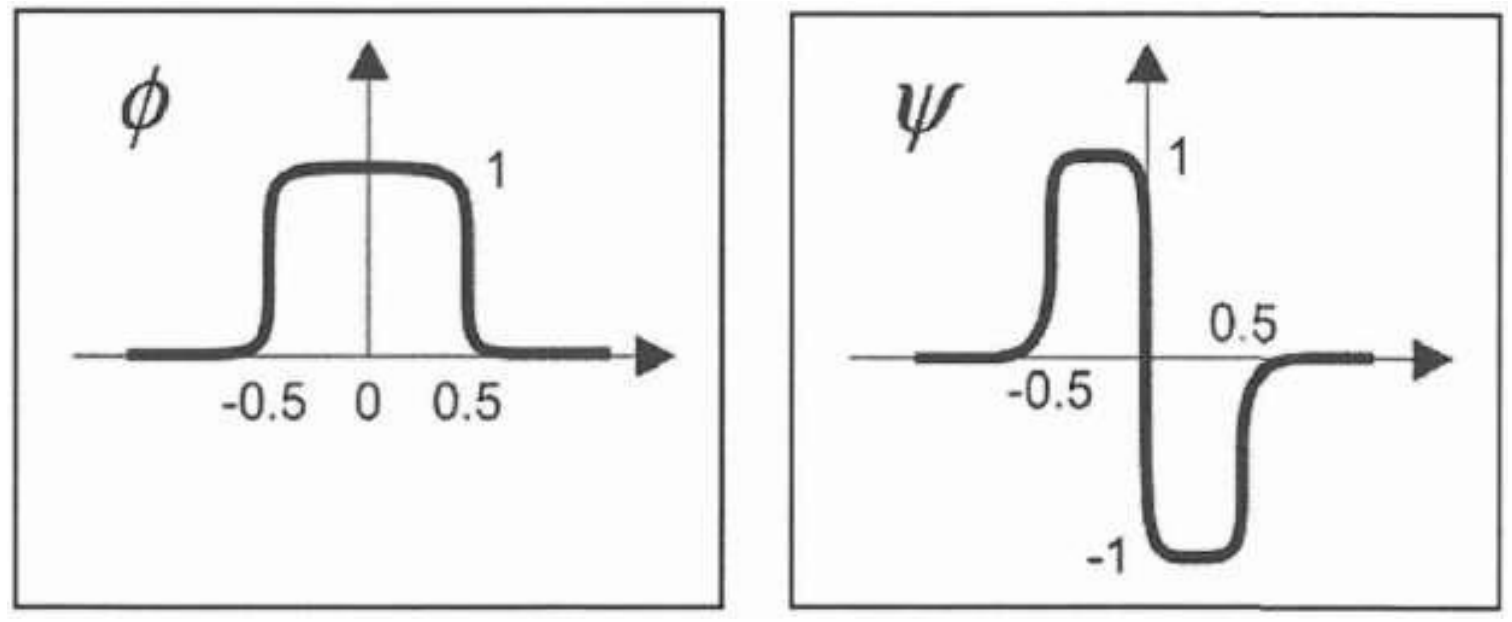

FIGURE 4: REAL SCALING AND WAVELET FUNCTIONS 
The engineer carrying out the filtration may control the parameters that characterize the wavelet development or may be automatically set. In the list below, the parameters that will be controlled or automatic, and the effects of the controlled parameters are described in the sections below.

i. Post-filtration parameters (controlled)

ii. Threshold value (controlled)

iii. Choice of threshold function (controlled)

iv. Number of decomposition levels (automatic)

v. Starting data frequency/(controlled)

vi. Scaling and wavelet functions and $\psi$ (automatic)

The original time spacing, a, is quite significant, and the characteristics of a higher frequency will vanish in the first interpolation. Since acquisition times are not regular, picking the smallest time interval between successive raw data cannot be a solution, and it won't warrant the taking of raw data points.

Though it would involves one or several billion points, the smallest possible a (that is, the highest possible frequency) filtration with the original interpolation sampling of one-tenth of a second would help us not miss anything. In addition, beginning with a very high frequency has a big weakness. There is a mere replication of the time stepping for every extra level of decomposition. The frequency of the real noise might be missed, as the number of these decomposition layers is limited. The resolution is selecting an initial time stepping that meets the needs of an engineer. A time stepping of one second will function, although it will entail central processing unit (CPU) demands that may not be equivalent to it, and the demonizing of the production data may not be adequate. If the concern is not in high-frequency data, a time step of 1 minute will be very fast and more than enough. When one needs to pick the high frequency at a realistic expense, a time step of ten to twenty seconds is going to be a better appeasement.

The precise point of shut-in might not be exactly recognized, despite the fact that the data will still be useful to PTA, and it will be feasible to return to the raw data and selectively reload some important parts. 


\subsection{Kappa Software (Saphir)}

Saphir is the industry standard PTA software, used by nearly all major IOC's, NOC's, Independents and Service Companies. Its simple user interface and workflow allows for fast training and self-learning for occasional users. For the advanced user, it offers a unique combination of analysis tools, analytical models and numerical models which can connect to other dynamic data application such as Topaze NL for Rate Transient Analysis and Rubis for fullfield history matching.

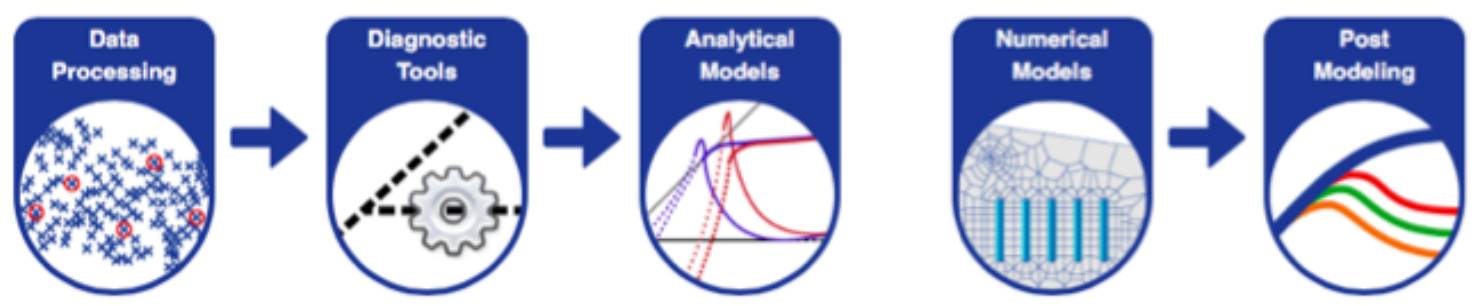

FIGURE 5: SAPHIR WORKFLOW (kappaeng website)

\section{Data loading in KAPPA- Workstation}

Saphir can load an unlimited number of gauges, rates, pressure and other data in almost any format includng ASCII, Excel.

\section{Data transfer from KAPPA-Server}

Saphir has real time links with acquisition systems, data drag and drop from other KAPPA workstation and modules KAPPA server which can identify build ups.

\section{Log-log analysis tools}

Interactive analysis tools are overlaid directly on the type curve to identify flow regimes. 


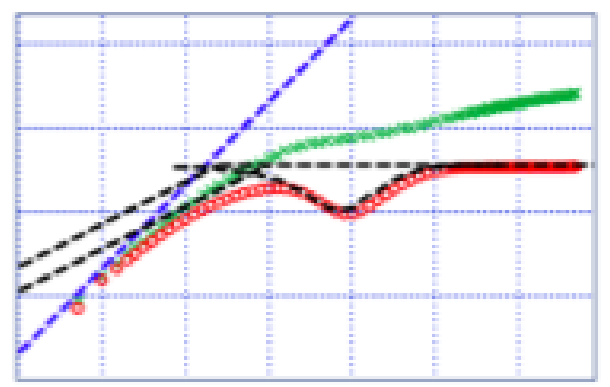

FIGURE 6: ANALYSIS PLOT

- Semilog plot: In a semi logarithmic graph, one axis has a logarithmic scale and the other axis has a linear scale. The idea here is we use semilog graph axes so we can more easily see details for small values of $y$ as well as large values of $y$.

\section{Analytical models}

Software offers a comprehensive built in analytical catalog combining well, reservoir and boundary models, complemented by external models.

Different wellbore, well, reservoir and boundaries can be combined to simulate a wide range of reservoir models.

Additional capabilities include rate dependent skin, changing wellbore storage, interference from other wells, gas material balance correction, well model changing in time, horizontal and vertical anisotropy.

- Wellbore models

- Well models

- Reservoir models

- Boundary models

- External models 


\section{Numerical models}

Numerical models are used for geometries beyond the scope of analytical models. This is predominantly 2D but with 3D refinement where needed. These numerical models also address nonlinearity.

Pseudo pressures are replaced by the exact diffusion equations for real gas, non- Darcy flow, pressure related physical properties, multiphase flow, water and gas injections, water drivers and desorption models for shale gas.

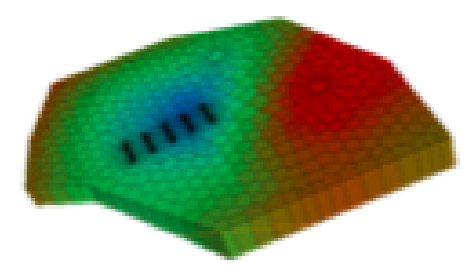

FIGURE 7: NUMERICAL MODEL 


\section{CHAPTER 3: DYNAMIC PRESSURE TRANSIENT ANALYSIS WORKFLOW}

The following steps are used in this project for the dynamic pressure transient analysis workflow:

1- Data collection

2- Data Analysis and Interpretation

3- Results

\subsection{Data collection:}

In the workflow, the first undertaking necessitates the setting up of the field. As usual, this mission is done once only. Information like location, name, reference, time and date for the start of data collection, and so on are entered throughout the field setup. Other common field properties that are also can also entered are relative permeability data and pressure/volume/temperature (PVT). A map of the field can also be loaded here, which demonstrates a variety of well locations. Later on, this map can be digitized and applied in multi well test analysis in studying how the nearby wells affects the pressure behavior of a certain well that is being investigated. The next step is adding each and every well in the field and carry on to organize the data tags for every well.

Examples of typical data tags are surface pressures, the downhole pressures and flow rates. In point of fact, there are two pressure gauges that are established in the majority of these wells. Data tag configuration necessitates the association of every tag name in the field setup having a subsequent tag name in the data historian or repository. The system gives room for the connection any source of data.

\subsubsection{Mirroring}

Rating the data into the system and Loading pressure starts with a process known as mirroring. The system examines the Oracle data warehouse for flow rate data and the high-frequency pressure in their initial state during this process.

The original data are indexed, compressed and stocked up as a twofold file in this method, and a consistently spaced condensed data set is exhibited on the screen so that they can be inspected.

The data reduction ratio that is used for display is user-defined, and has a default set at one thousand. 
The process of mirroring guarantees the availability of all the gauge data for swift processing, elegant cleansing and filtration, before the interpretation and analysis.

In every 2 hours, the mirroring process is repeated by default, whereby any new data that is obtained in the data repository are appended and loaded to the accessible data that is reflected in the system. This automated update process guarantees the availability of permanent sensor data in actual time for the user. The client can set the process of update to take place regularly as it is necessary.

\subsubsection{Data Reduction}

Since the raw data that comes from the permanent sensors are bulky and most of the time goes along with outliers and noise, the data has to be denoised before filtering them down to a realistic size to ease interpretation and analysis. To guarantee a smart filtration and denoising, the system carries out this data reduction with the use of wavelet-based algorithm. In order for outlier or noise to be removed, the wavelet algorithm is the determiner of the trend in the data and offers the user with an adjustable ribbon or band in the region of the data set. The data points that are outside this band are discarded as outliers or noise. For smart data filtration, the wavelet algorithm is applied, which guarantees the preservation of all significant events, like shut-ins. Figure 6 shows an example of wavelet denoising with the aid of the adjustable ribbon. The wavelet data filtration algorithm necessitates the original data set to be spaced evenly. The system otherwise fills in any irregular space that have interpolated data. The system offers the facility that stores and creates a filtered data set from the reflected raw data.

The user has the alternative of using the system default filter settings or to overriding them during the original filtration setup. These settings will be applied automatically to any successive raw data that is obtained and appended to the presented filtered data set. The user may however go back to any part of the data locally and history repopulates any significant sequences, like shut-in periods needed for PTA. The accessibility of the reflected raw data makes this to be very fast and feasible. 


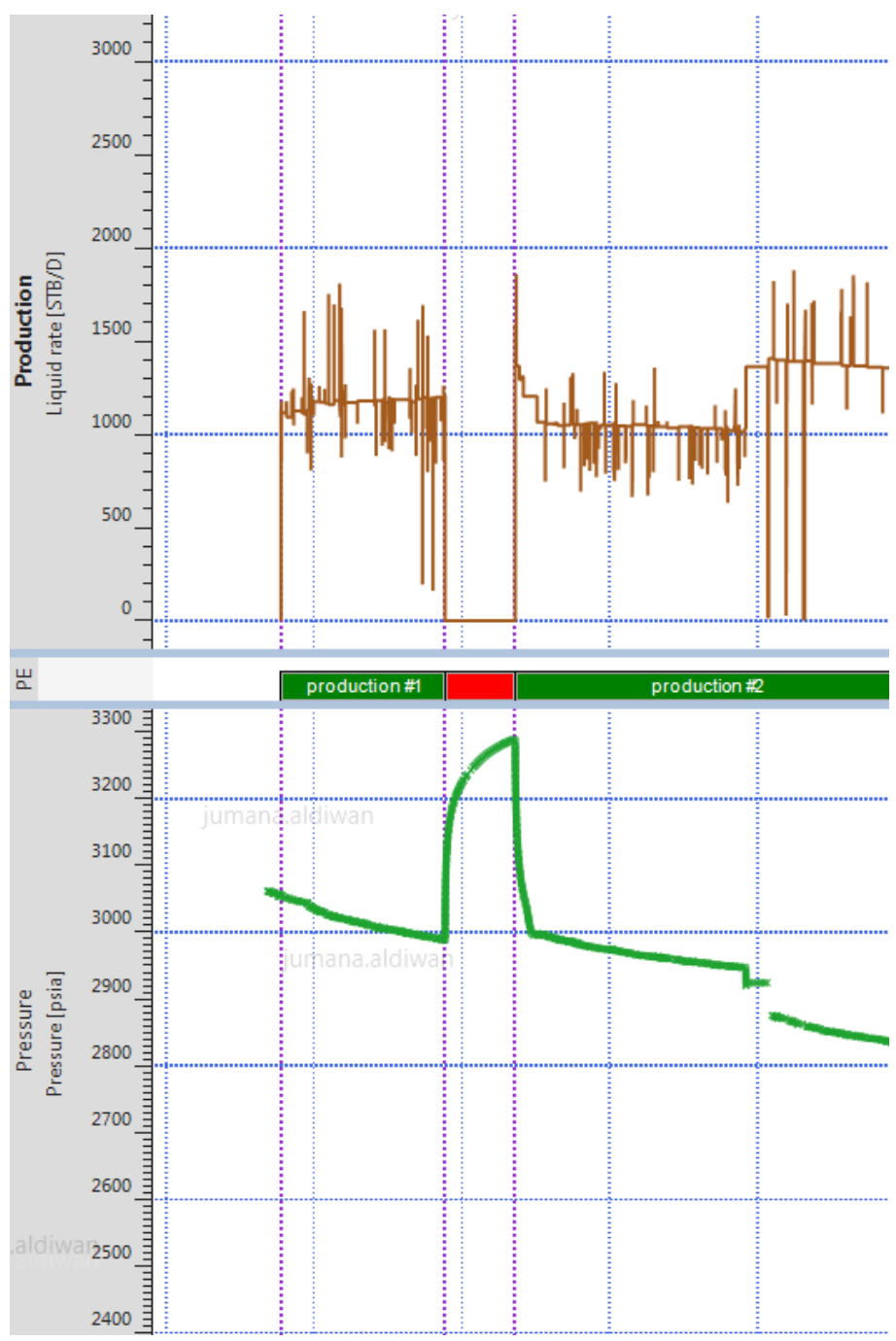

\section{FIGURE 8: EXAMPLE OF PDHMS DATA NOISE AND OUTLIER REMOVAL USING WAVELET ALGORITHM}

\subsubsection{Data Quality Control}

Before conducting any data analysis, it is important to quality-check the data to ensure consistency. The flow rate data and the pressure data have to be synchronized to allow the PTA to proceed. In most cases, shut-in periods are obviously detectable on pressure gauge data. The flow rate account, however, is unlikely to give obvious void (zero-rate) portions that are synchronized with the pressure data's shut-in periods. As a result, there is need for some adjustments to bring the rate to zero, where shut-in is shown. 
The system offers a capacity to generate a derived or secondary medium, where the rate history is regenerated to be in synchrony with the pressure data for the period of shut-in. The rate, in the regenerated production record, is put to zero every time a shut-in is observed in the pressure data and maintained in its default values wherever else.

\subsection{Data Analysis and Interpretation}

Nonlinear regression is used to optimize the model parameters. This may be automatic or user controlled from a list of variable parameters, an acceptable range and weighting of the data. Optimization may be performed on the extracted period(s) or on the whole production history. Confidence intervals may be displayed. Sensitivity analysis may be performed on the same model using different parameters.

A transient (rate or pressure) investigation and analysis can start once the pressure and production record data have been quality-checked and synchronized. The transient rate and pressure analysis applications make up part of a group of interrelated applications that make the data transfer more efficient. The operator just clicks on the expected gauge, then click on the next icon to transmit the data. Investigation and analysis can therefore be performed using all the contemporary apparatus available, which include well parameter estimation, nonlinear regression for reservoir and pressure derivative diagnostic plots. In case the user is dissatisfied with the analysis, may be due to the over filtering of pressure, the system will offer the facility of going back and sampling the pressure data once more.

If necessary, the user has the alternative of including more pressure data points or using all the raw pressure data. Figure 9 shows an example of multiple pressure buildup analysis using PDHMS data. Pressure buildup analysis of this kind might be applied in tracking any changes in wellbore condition (skin) and reservoir properties over time.

Something else that has to be mentioned is the fact that the third buildup was the consequence of plant shut down for maintenance intentions but not a planned shut-in.

Flow Regimes Sequences:

- Early flow/shut-in sequences are used to estimate initial reservoir pressure.

- Extended flow sequence used to "sample" near-well reservoir volume.

- Extended shut-in sequence used to estimate near-well reservoir properties. 


\section{Common Flow Regimes:}

- Wellbore Storage (WBS): "Unit Slope" trend (straight line on log-log plot).

- Infinite-Acting Radial Flow (IARF): Semilog plot relation.

- Formation Linear Flow (FLF): Fractured wells, high conductivity fracture.
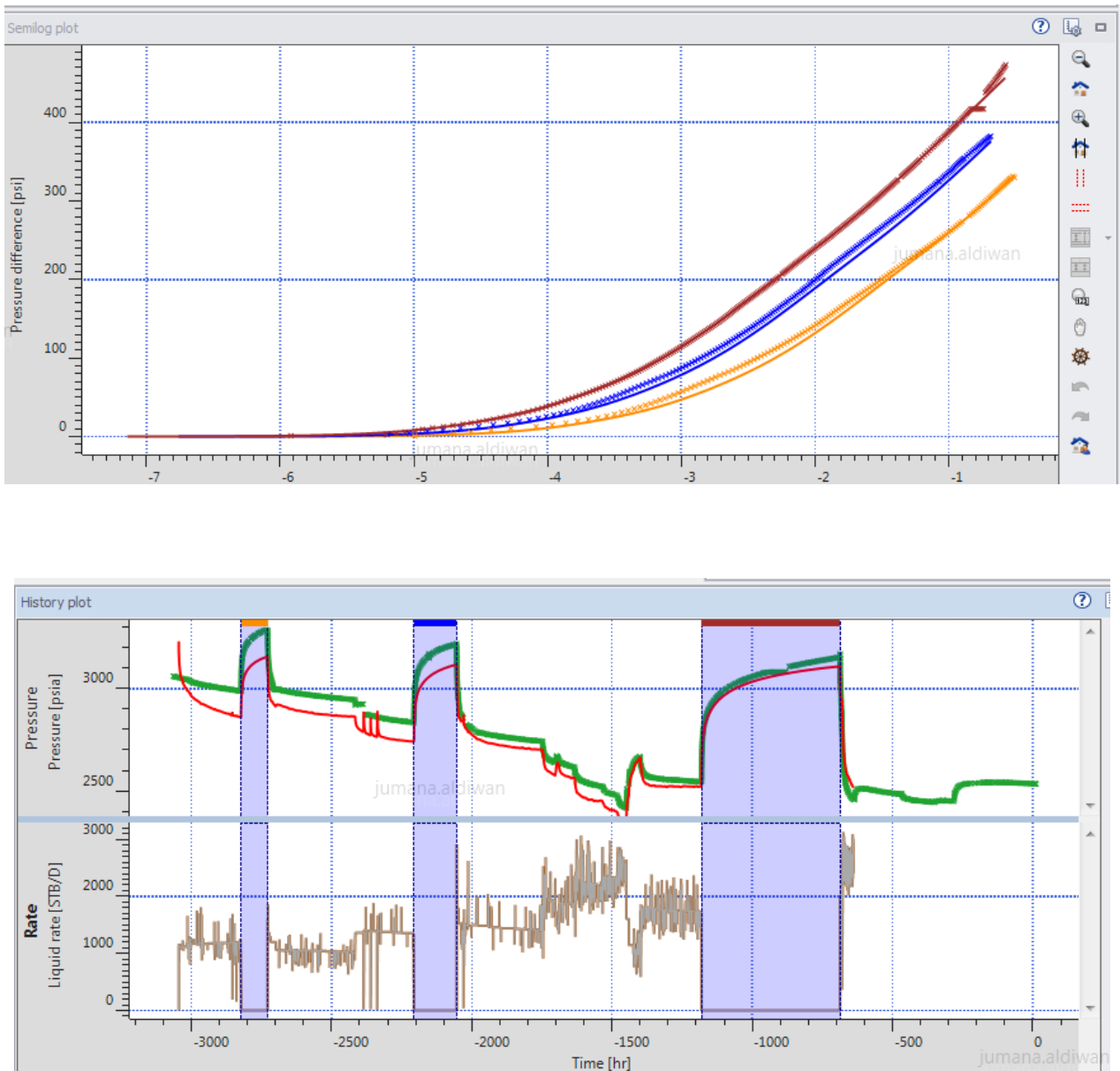

Fig. 9: Multiple pressure buildup analysis using PDHMS data 


\section{TABLE 3: EQUATIONS OF DATA ANALYSIS}

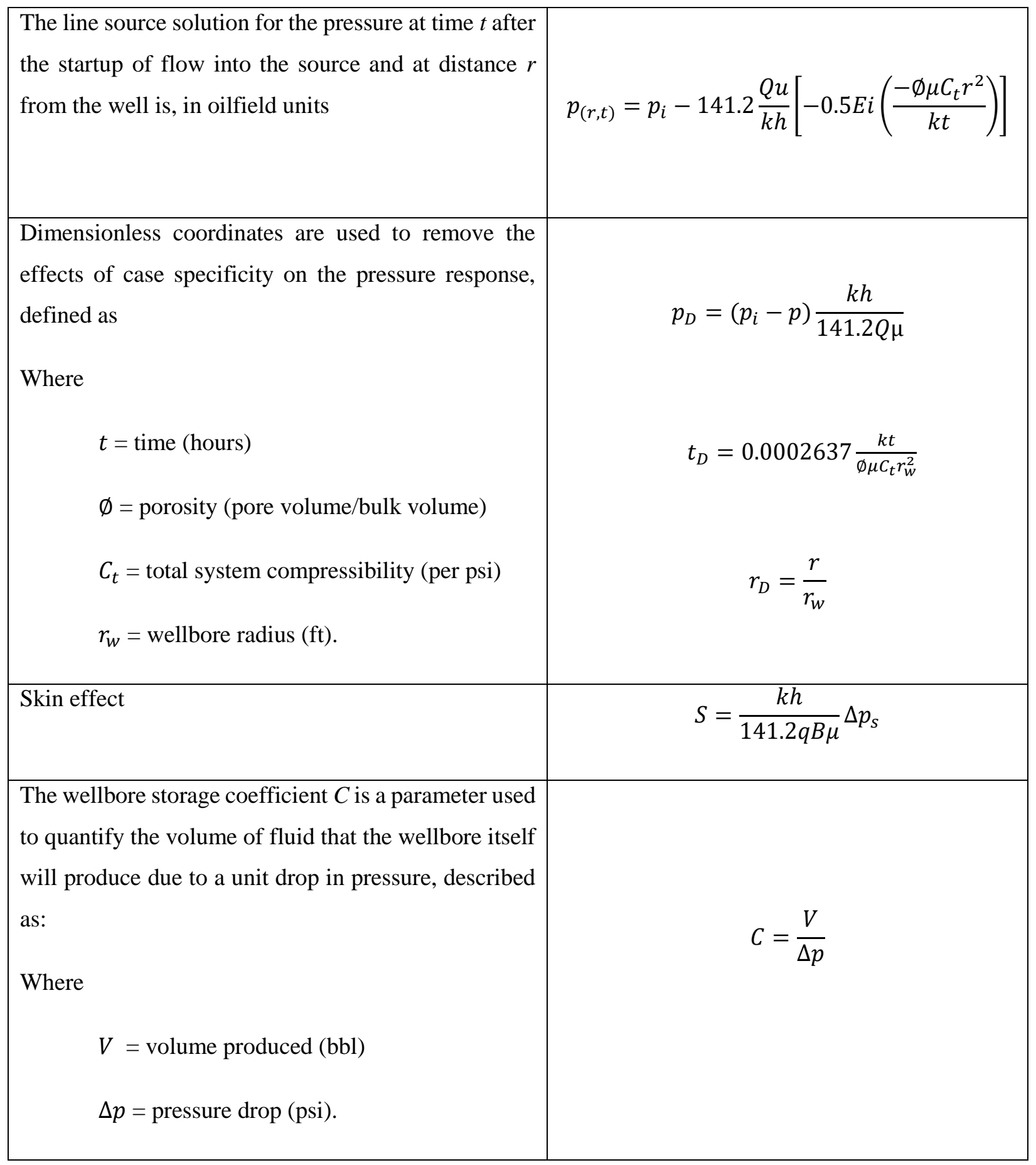




\begin{tabular}{l}
$\begin{array}{l}\text { From the expressions of the dimensionless } \\
\text { coordinatest } t_{D}, C_{D} \text {, and } P_{D} \text { and from the pressure } \\
\text { match, permeability thickness product } k h \text { can be } \\
\text { calculated as: }\end{array}$ \\
Where \\
$\qquad M_{p}=$ pressure match. \\
$\begin{array}{l}\text { From the time match, the wellbore storage (WBS) } \\
\text { constant } C \text { can be calculated as: } \\
\text { Where } \\
\qquad M_{t}=\text { time match. }\end{array}$ \\
\hline $\begin{array}{l}\text { The value of } C_{D} \text { can be calculated from the WBS } \\
\text { constant } C \text { as }\end{array}$ \\
\hline $\begin{array}{l}\text { From the skin match, the skin factor can be calculated } \\
\text { as }\end{array}$
\end{tabular}

\subsection{Results}

Specialized analysis plots (log-log plot - Semi-log plot) can be created with options tailored to specific flow regimes when the interpretation and analysis were completed, the analysis outcome, in addition to the intact analysis file including production history data and the accompanying pressure, were ready to be archived. In the system directory, a pointer to the file location can also be established. This guarantees the availability of results and well test analysis files in the same system to be used in future. 


\section{CHAPTER 4: CASE STUDIES}

For characterizing the reservoir and evaluating well performance with pressure transient analysis, two (2) case studies will be completed using real-time data from permanent downhole pressure gauges.

\subsection{Case 1:}

\subsubsection{Data collection:}

Field description: The field is a north-south-trending anticline $22 \mathrm{mi}[37 \mathrm{~km}]$ long and $4 \mathrm{mi}[7 \mathrm{~km}]$ wide, and contains two productive sandstone reservoirs.

Well description: the well in Case 1 was completed in June 2008 as a cased-hole horizontal producer. Formation analysis logs for Case 1 are shown in Figure 12. The well was equipped with a packer for zonal isolation and a permanent downhole monitoring system (PDHMS) for reservoir monitoring.

Type of reservoir: Sandstone oil field

The main model parameters are as follows:

- Porosity $\varnothing=17 \%$

- Well radius $r_{w}=0.3 \mathrm{ft}$.

- Pay zone $h=90 \mathrm{ft}$.

- Formation compressibility $=3 \mathrm{E}-6 \mathrm{psi}^{-1}$

- Fluid type is oil

- Volume factor $B=1.66 \mathrm{~B} / \mathrm{STB}$

- Viscosity $\mu=0.362 \mathrm{cp}$

- Total compressibility $c_{t}=3 \mathrm{E}-6 \mathrm{psi}^{-1}$

- $P_{i}=3232.16 \mathrm{psi}$

- Effective well length $L_{w}=1,024.51 \mathrm{ft}$.

- $Z w=75.4184 \mathrm{ft}$. 


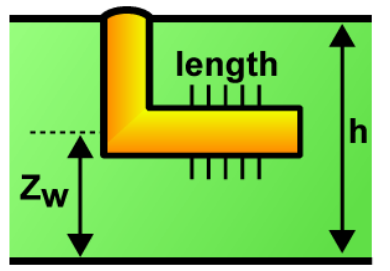

FIGURE. 10: WELL PARAMETERS

The reservoir and boundary parameters are as follows (Figure. 11):

- $h=90 \mathrm{ft}$

- $\quad k h=790$ md-ft.

- $k=8.77 \mathrm{md}$

- $k z / k r=0.0146$

- $\quad$ Radius of investigation $R_{i n v}=4,428.42 \mathrm{ft}$.

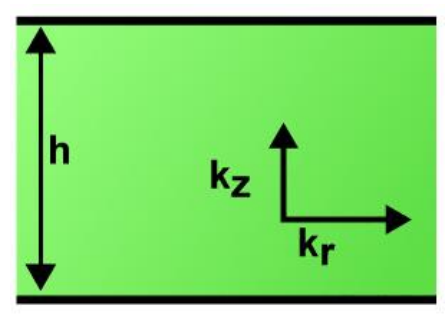

FIGURE. 11: RESERVOIR PARAMETERS 


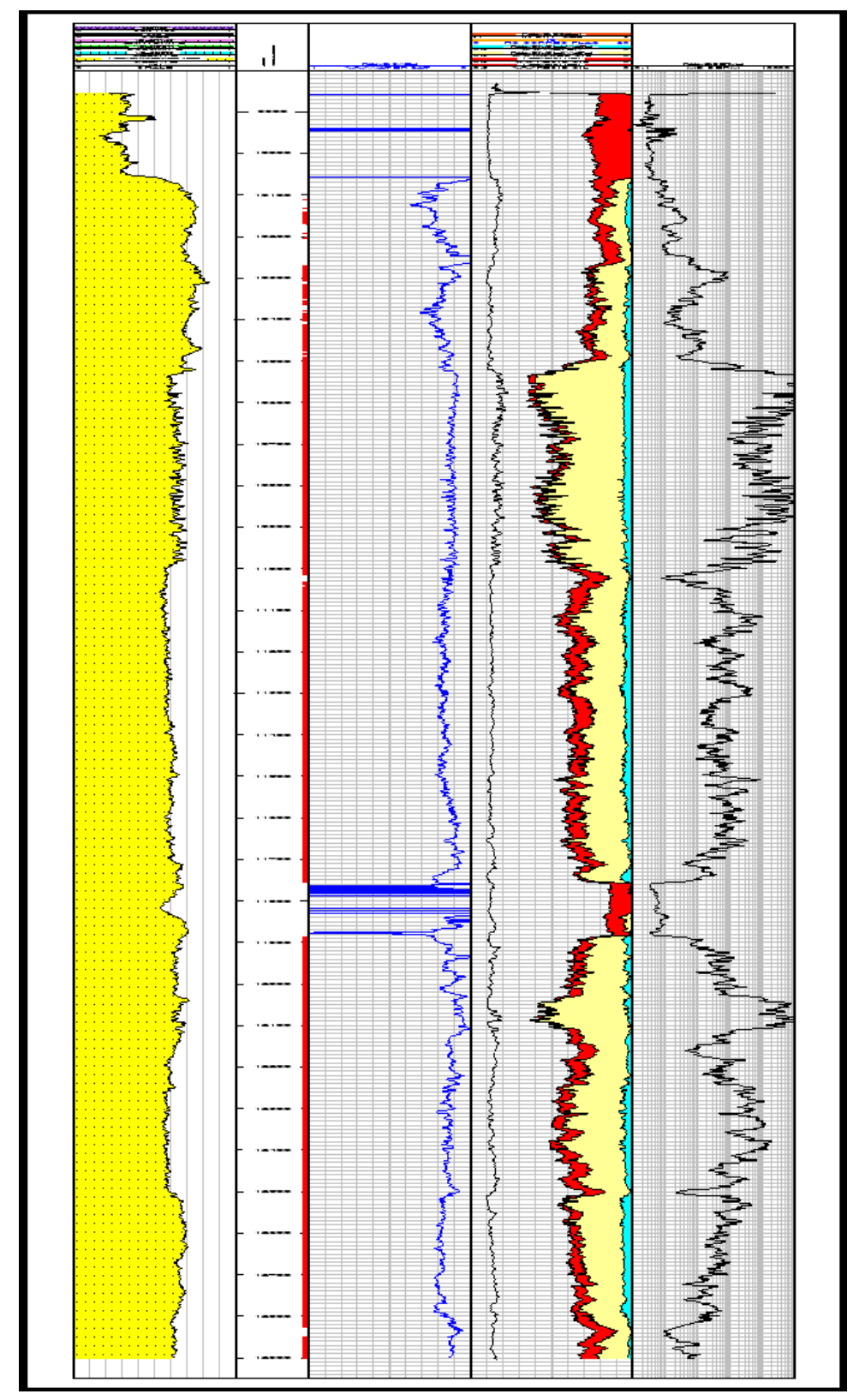

FIGURE.12: FORMATION ANALYSIS LOGS FOR CASE 1 
Data: Figure 13 shows the downhole pressure and rate readings. These data cover a period of 3,200 hours [133+ days] with 5,540 pressure points and 1,480 rate points. In this dataset, there are three distinct buildups.

The last build up was selected for analysis because it is preceded by a long shut in period which can provide a good match with the model.

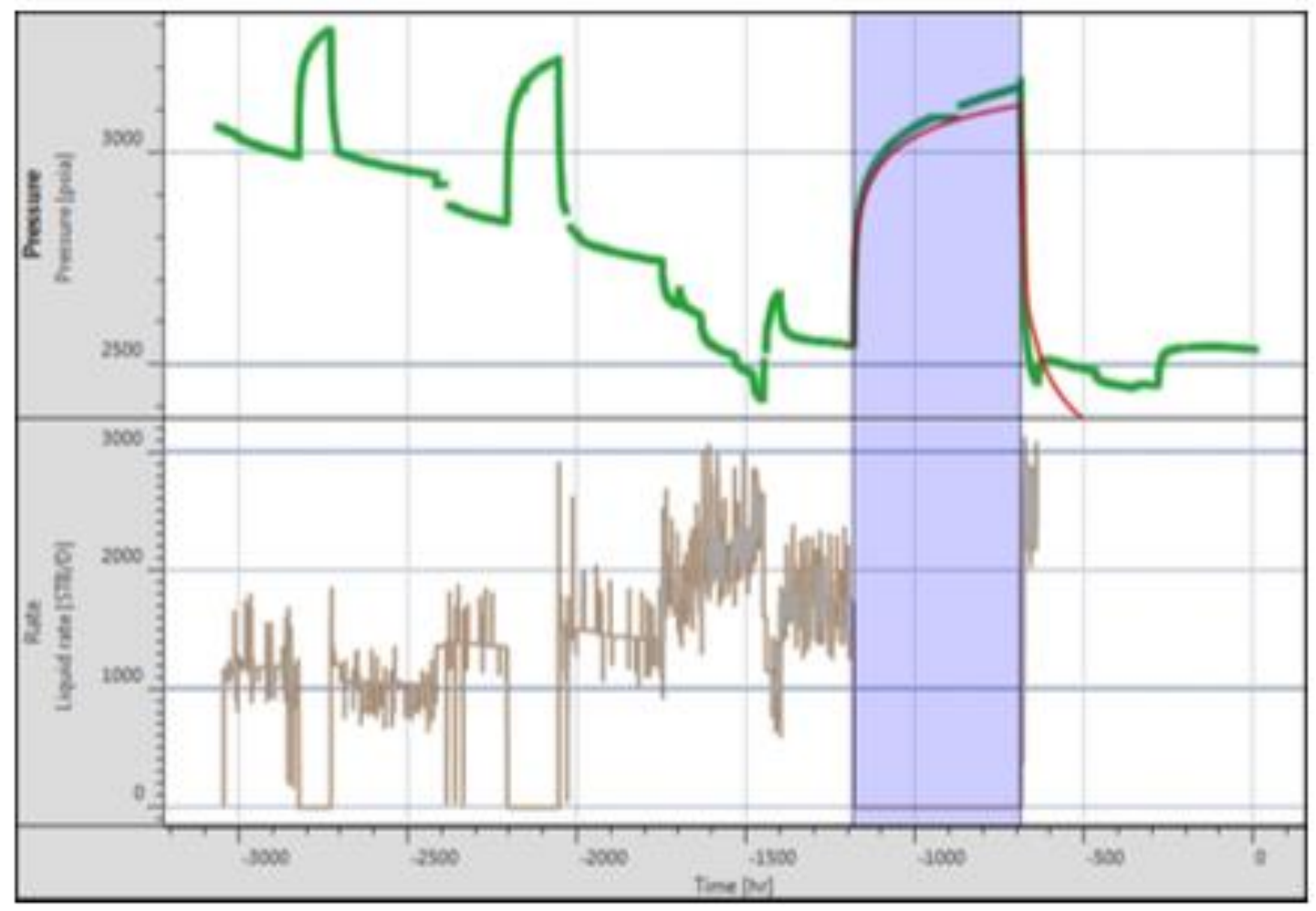

FIGURE. 13: CASE 1 DATA

\subsubsection{Data Analysis and Interpretation:}

A horizontal well model was used to match the data with changing WBS in an infinite-boundary homogeneous reservoir.

Followings are the results of the analysis with the model:

- $M_{t}=4.7 \mathrm{hr}^{-1}$

- $M_{p}=0.00535 \mathrm{psi}^{-1}$

- $C=0.1359 \mathrm{bbl} / \mathrm{psi}$ 
- $\quad$ Total skin $=-6.25$

- $k h_{\text {total }}=790 \mathrm{md}-\mathrm{ft}$

- $\mathrm{k}_{\mathrm{avg}}=8.77 \mathrm{md}$

The horizontal well is used in this reservoir to ensure better recovery, fewer number of wells and lower field development cost. It appears from the pressure response over the radius investigation (4428.42 ft.) that the reservoir behaves as a homogeneous reservoir. This is also consistent with the geological description of the reservoir.

Figure14 shows the data overlaid with the model match. Given that no prior stimulation was conducted on this well, the negative skin could possibly be attributed to geoskin or fissures (near the wellbore).

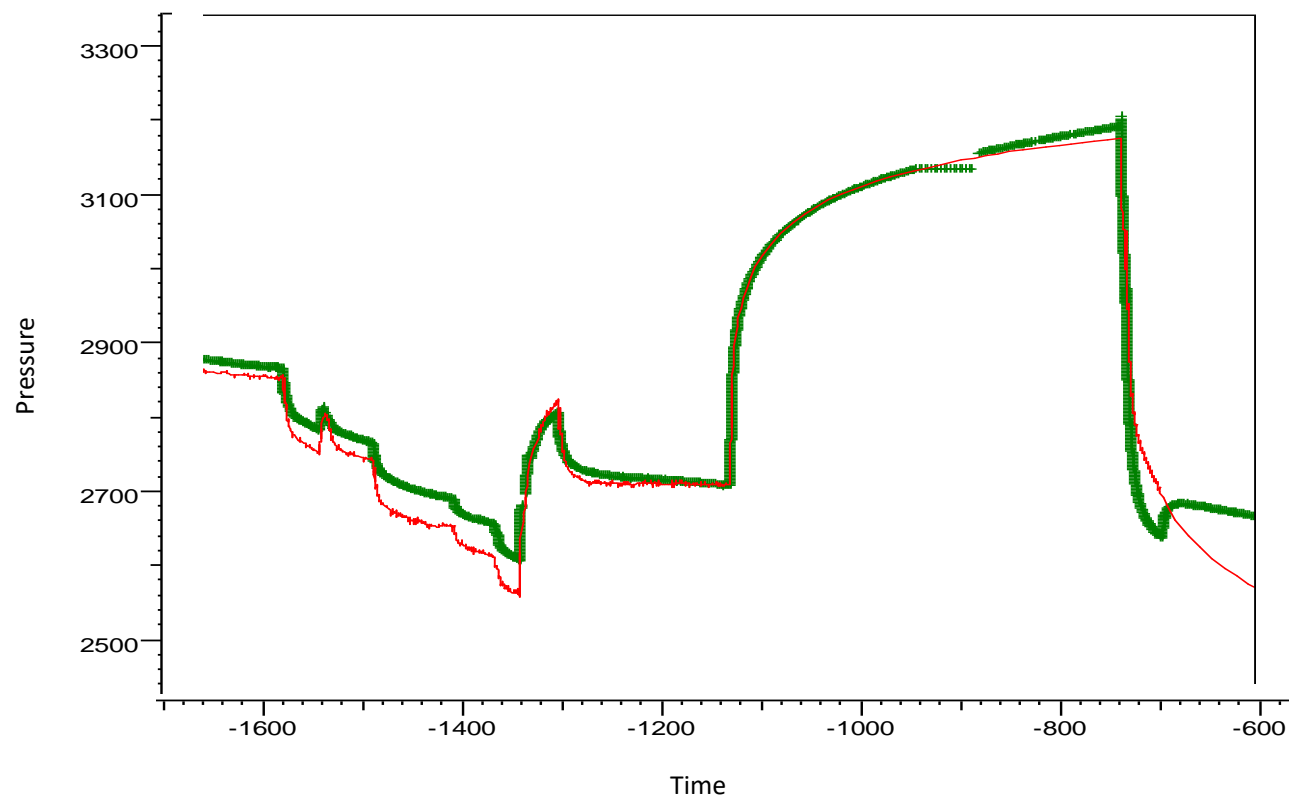

FIGURE. 14: CASE 1 SIMULTED DATA

\subsubsection{Results:}

Figure 15 and 16 show the log-log and semilog analysis, respectfully, of the last buildup. Semilog Plot presented the schematic of the separate and combined influences of skin and WBS Also the Skin effect and wellbore storage (WBS) yield a unique combined influence. 


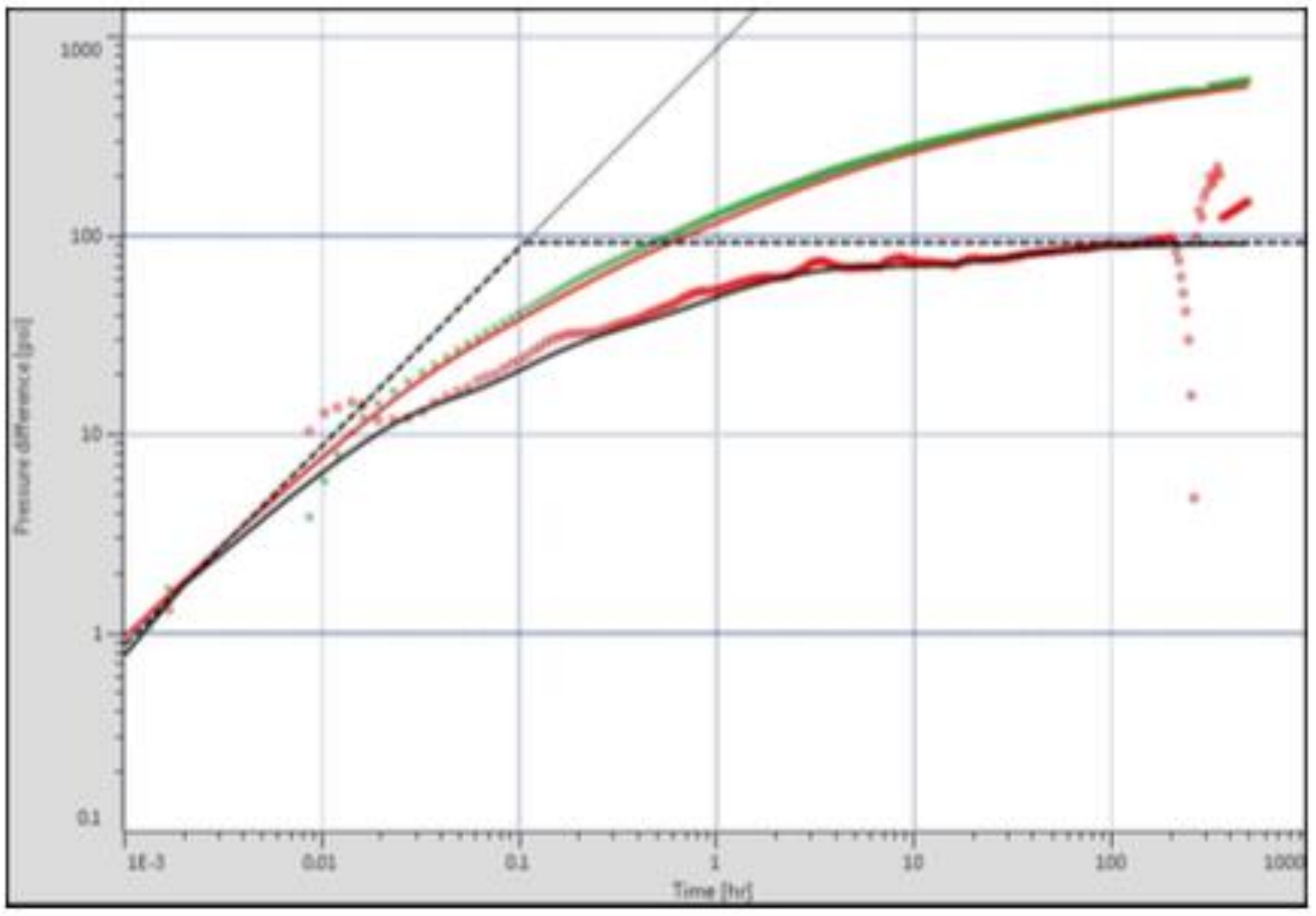

- Diminution less pressure/ Diminution Less time

- Derivative

FIGURE. 15: LOG-LOG ANALYSIS OF THE LAST BUILDUP FOR CASE (1)

Log-Log Plot presented the effect of separate and combined influences of skin and WBS. Also the function of horizontal for infinite-acting radial flow (IARF) flow regime. 


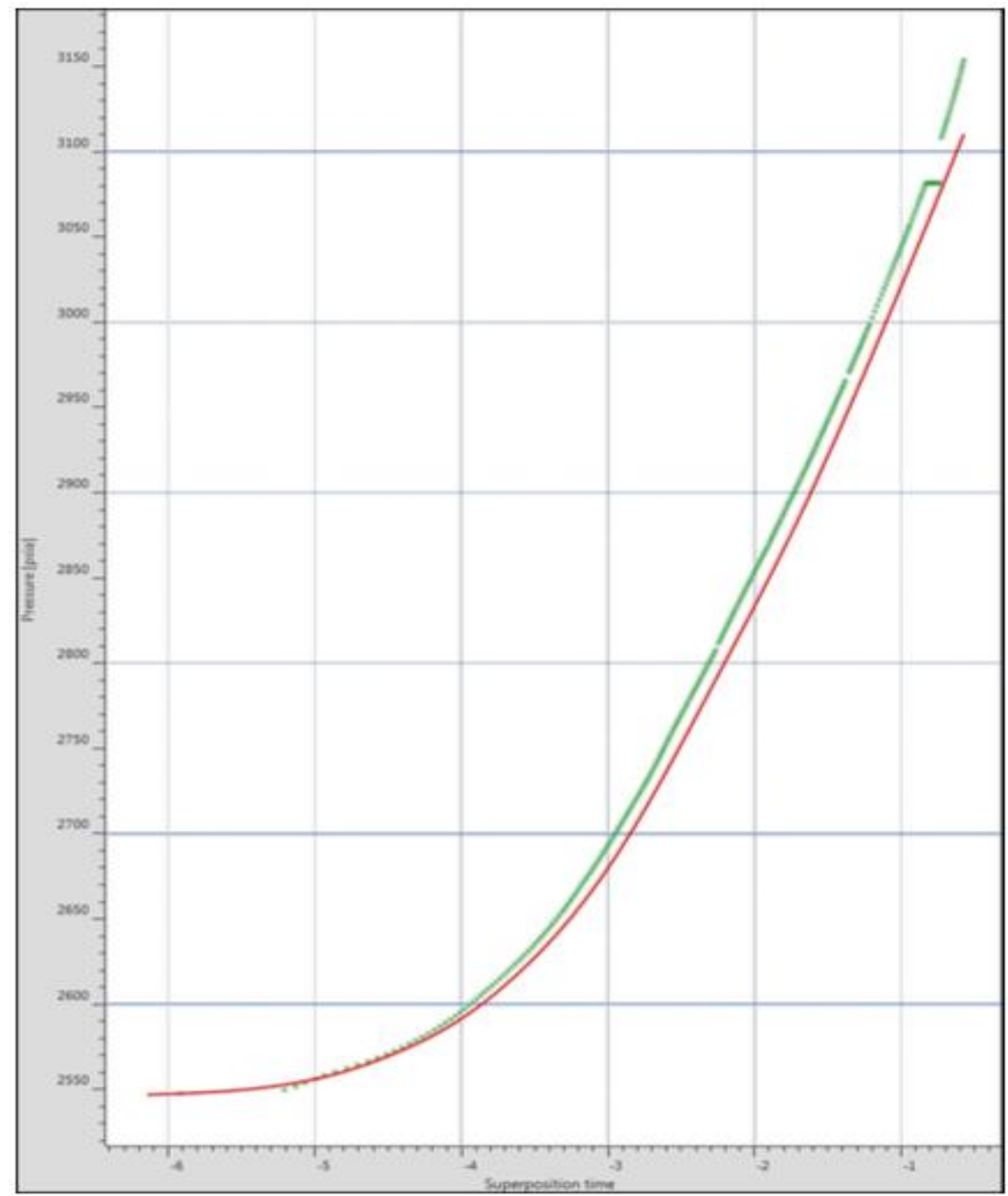

- Diminution less pressure/ Diminution Less time

- Derivative

FIGURE. 16: SEMILOG ANALYSIS OF THE LAST BUILDUP FOR CASE (1) 


\subsection{Case 2:}

\subsubsection{Data collection:}

Field description: This field is a north-south-trending asymmetrical anticline. The eastern flank is slightly steeper than the regional dip, averaging approximately $2^{0}$, while the western flank steepens to a maximum dip of $8.7^{0}$. The length of the field is approximately $90 \mathrm{~km}$, and the width of the field ranges from 5 to 17 $\mathrm{km}$. There are three oil-bearing carbonate reservoirs.

Well description: The well in Case 2 was completed in May 2008 as an openhole horizontal producer. Figure. 17 shows Case 2 Formation analysis logs. The well is equipped with an electrical submersible pump (ESP) and a Y-tool on 41/2-in. tubing. It also has a PDHMS for reservoir monitoring. Figure. 18 shows a cross section of Case 2. This well was a subject to well acid stimulation, shown as the highlighted interval in Figure. 17

Type of reservoir: Carbonate

The main model parameters are as follows:

- Porosity $\emptyset=18 \%$

- Well radius $r_{w}=0.3542 \mathrm{ft}$.

- Pay zone $h=110 \mathrm{ft}$.

- Formation compressibility $=3 \mathrm{E}-6 \mathrm{psi}^{-1}$

- Fluid type is oil

- Volume factor $B=1.168 \mathrm{~B} / \mathrm{STB}$

- Viscosity $\mu=1.83 \mathrm{cp}$

- Total compressibility $c_{t}=3 \mathrm{E}-6 \mathrm{psi}^{-1}$

- $P_{i}=1,6651.19$ psi

- $\quad$ Effective well length $L_{w}=1,1816.09 \mathrm{ft}$.

- $Z w=55 \mathrm{ft}$. 
The reservoir and boundary parameters are as follows:

- $h=110 \mathrm{ft}$.

- $\quad k h=10,600 \mathrm{md}-\mathrm{ft}$

- $\quad k=96.36 \mathrm{md}$

- $k z / k r=0.421$

- $\quad$ Radius of investigation $R_{i n v}=786.32 \mathrm{ft}$.

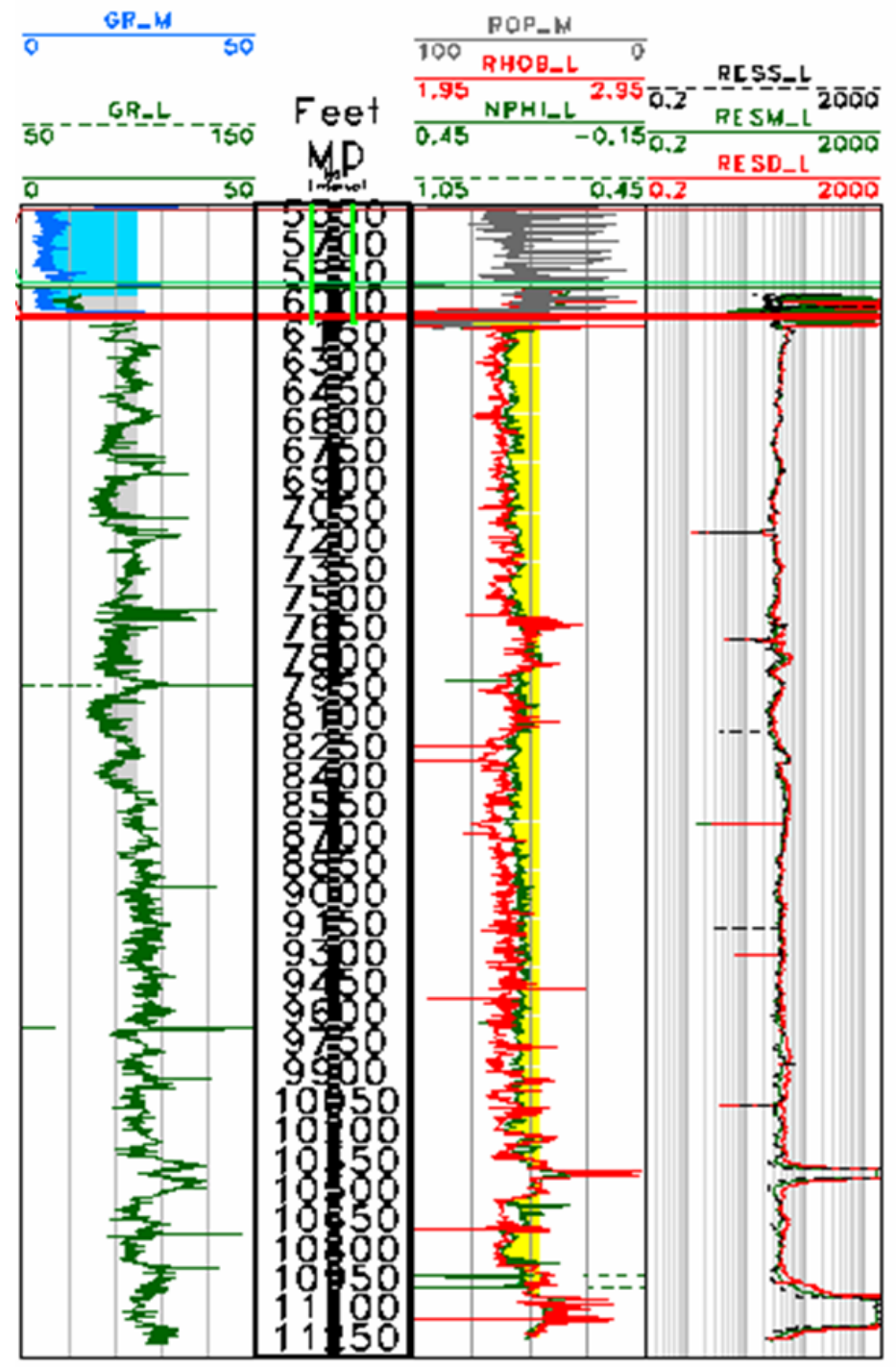

FIGURE. 17: CASE 2 FORMATION ANALYSIS LOGS 


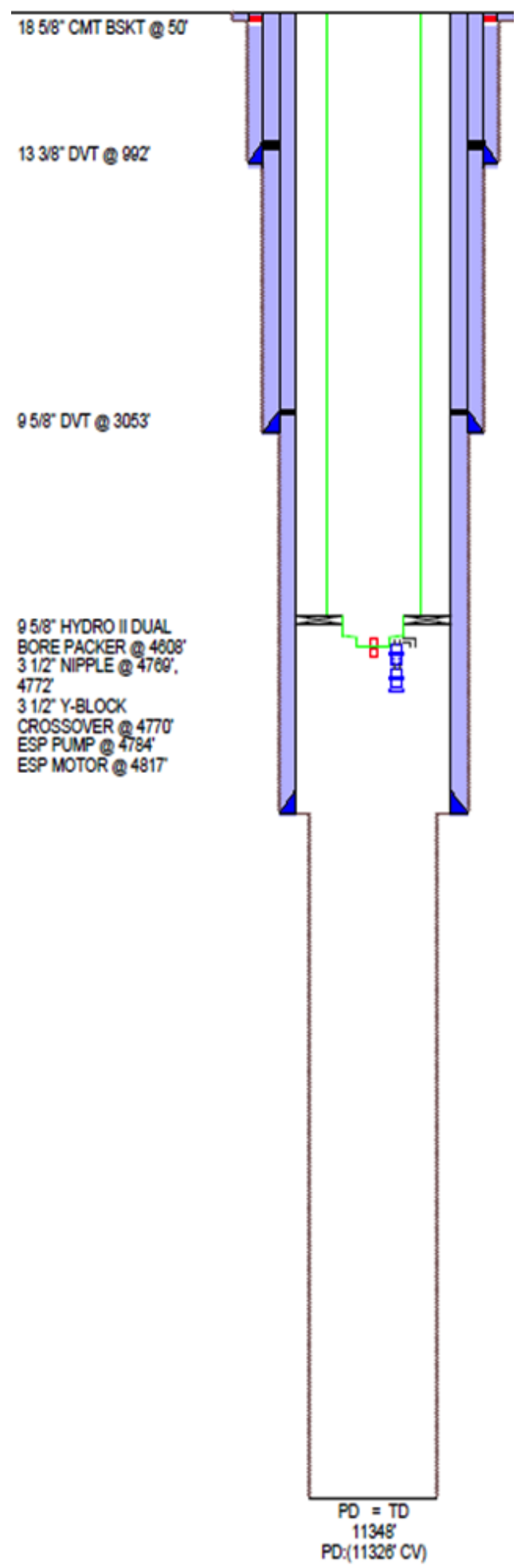

FIGURE. 18: CASE 2 WELL CROSS SECTION 
Data: Figure. 19 shows the real-time data downhole pressure and rate data. These data cover a period of 1,800 hours [75 days] with 12,541 pressure points and 574 rate points.

The last build up was selected for analysis because it is preceded by a long shut in period which can provide a good match with the model.

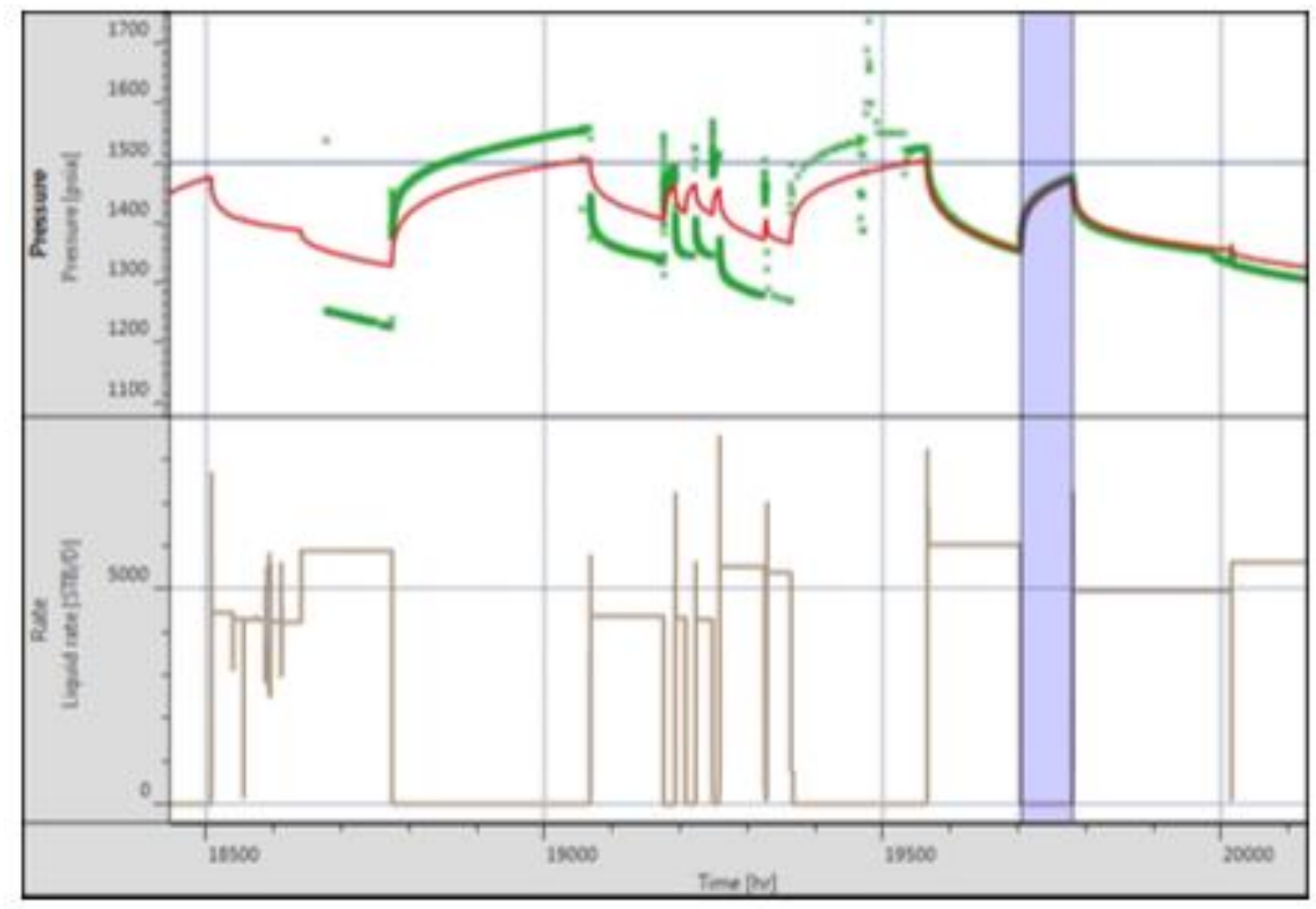

FIGURE. 19: CASE 2 DATA

\subsubsection{Data Analysis and Interpretation:}

A horizontal well model was used to match the data with changing Wellbore Storage (WBS) in an infiniteboundary homogeneous reservoir.

The followings are the results of the analysis with the model:

- $M_{t}=0.292 \mathrm{hr}^{-1}$

- $M_{p}=0.0058 \mathrm{psi}^{-1}$

- $C=5.83 \mathrm{bbl} / \mathrm{psi}$

- Total skin $=-7.03$ 
- $k h_{\text {total }}=10,600 \mathrm{md} . \mathrm{ft}$

- $\quad \mathrm{k}_{\mathrm{avg}}=96.36 \mathrm{md}$

The horizontal well is used in this reservoir to ensure better recovery, fewer number of wells and lower field development cost. It appears from the pressure response over the radius investigation (786.323 ft.) that the reservoir behaves as a homogeneous reservoir. This is also consistent with the geological description of the reservoir.

\subsubsection{Results:}

The log-log analysis of the Pre-acid buildup is illustrated in Figure 20 and is compared with the $\log -\log$ analysis of the Post-acid period illustrated in Figure 21, where the test data were matched to a horizontal well model in a homogeneous reservoir with changing WBS. The model match indicates an effective horizontal length $L_{e}$ of 1,816 ft., which is a significant improvement over the previous value, 1,024 ft., determined from the Pre-acid test. The flow capacity was determined to be $10,600 \mathrm{md}-\mathrm{ft}$. The results also show a skin factor of -2.4 compared with the Pre-Acid value of zero. Analysis of the test data indicates a very successful acid treatment and highlights the value of pressure transient analysis of PDHMS data in providing a reliable means to diagnosing the well and characterizing the reservoir.

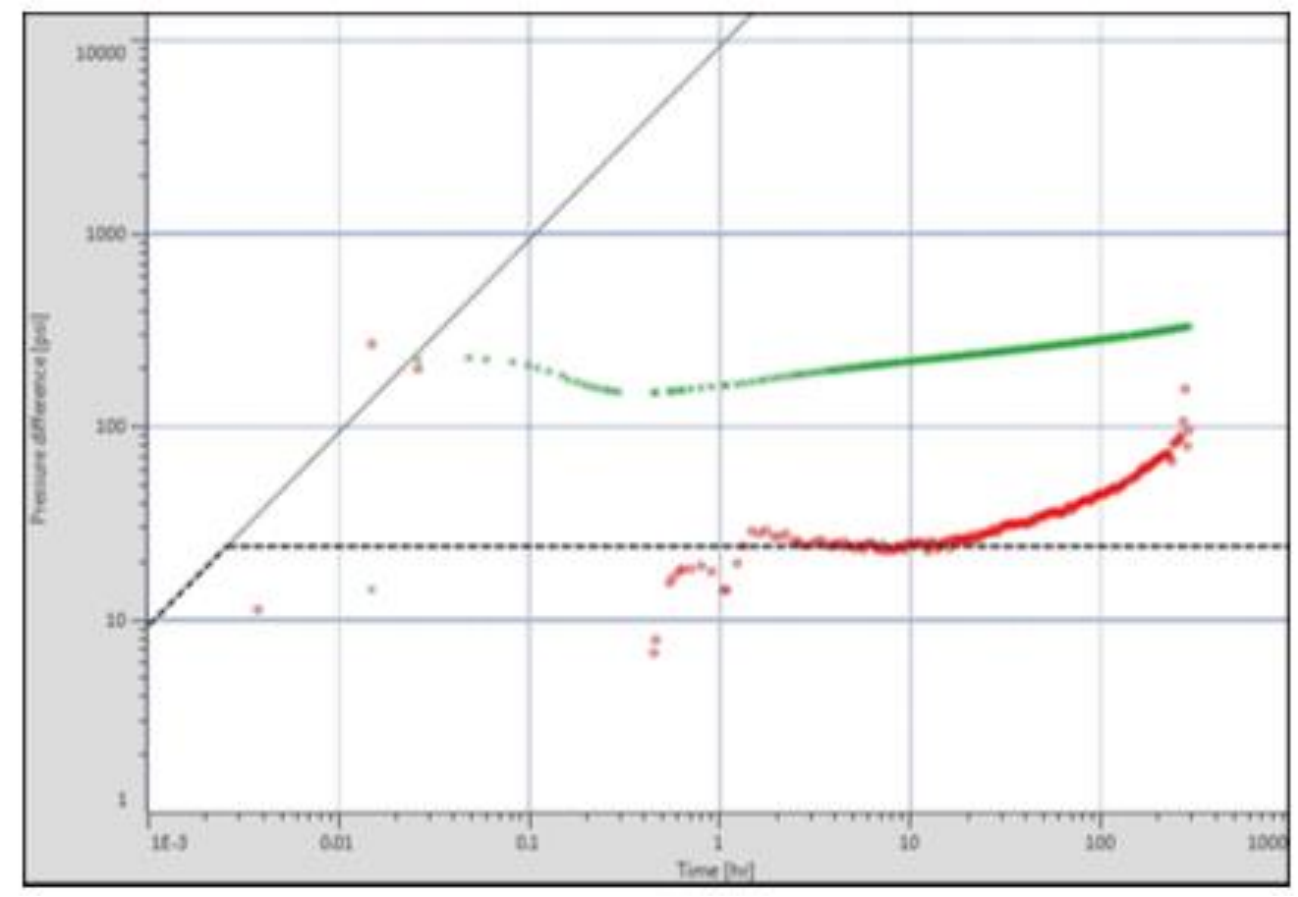

FIGURE. 20: PRE-ACID LOG-LOG ANALYSIS FOR CASE (2) 


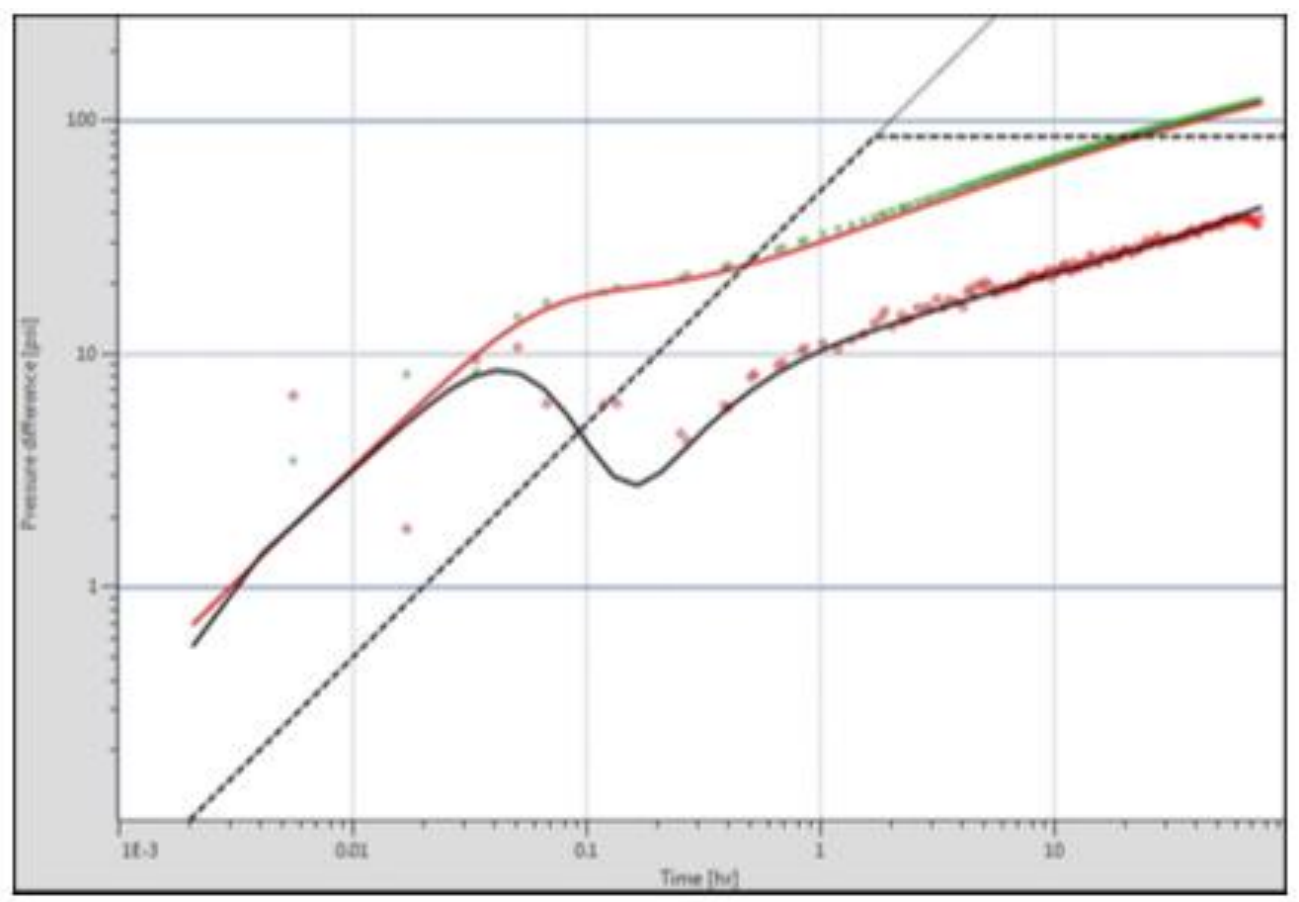

FIGURE. 21: POST-ACID LOG-LOG ANALYSIS FOR CASE (2)

- Diminution less pressure/ Diminution Less time

- Derivative 


\section{CONCLUSION}

The dynamic Pressure Transient Analysis workflow have been presented in this study, with the use of the Permanent Down hole Gauges according to the Intelligent Field initiative. The use of this workflow could lead to cost savings, as a result of decrease in the number of planned shut-ins for pressure buildup assessments. Using the long production history data captured by PDHMS to confirm that the flow period has the same results as the shut in period also allows for the estimate of permeability and skin damage in addition to hydrocarbons in place and reservoir boundaries, which generally necessitates well shut-in, and consequently, increases loss of production. 


\section{REFERENCES}

Athichanagorn, S., Horne, R. N., \& Kikani, J. (2002, October 1). Processing and Interpretation of LongTerm Data Acquired From Permanent Pressure Gauges. Society of Petroleum Engineers. doi:10.2118/80287-PA.

Chorneyko, D. M. (2006, January 1). Real-Time Reservoir Surveillance Utilizing Permanent Downhole Pressures - An Operator\&apos;s Experience. Society of Petroleum Engineers. doi:10.2118/103213-MS

Cinco-Ley, H., \& Samaniego V., F. (1989, January 1). Use and Misuse of the Superposition Time Function in Well Test Analysis. Society of Petroleum Engineers. doi:10.2118/19817-MS

De Oliveira Silva, M.I. and Kato, E.T. 2004. Reservoir Management Optimization Using Permanent Downhole Gauge Data. Paper SPE 90973 presented at the SPE Annual Technical Conference and Exhibition, Houston, Texas, USA, 26-29 September. doi: 10.2118/90973-MS.

Horne, R. N. (2007, December 1). Listening to the Reservoir-Interpreting Data From Permanent Downhole Gauges. Society of Petroleum Engineers. doi:10.2118/103513-JPT

Horner, D.R. 1951. Pressure Build-Up in Wells. Paper WPC 4135 presented at the $3^{\text {rd }}$ World Petroleum Congress, The Hague, The Netherlands, May 28- June 6.

Houzé, O., Viturat, D., and Fjaere, O.S. 2008. Dynamic Flow Analysis. KAPPA Engineering.

Miller, C. C., Dyes, A. B., \& Hutchinson, C. A. (1950, April 1). The Estimation of Permeability and Reservoir Pressure From Bottom Hole Pressure Build-Up Characteristics. Society of Petroleum Engineers. doi:10.2118/950091-G

Nestlerode, W. A. (1963, January 1). The Use Of Pressure Data From Permanently Installed Bottom Hole Pressure Gauges. Society of Petroleum Engineers. doi:10.2118/590-MS

Ortiz, C.E.P., Auguiar, R.B., and Pires, A.P. 2009. Wavelet Filtering of Permanent Downhole Gauge Data. Paper SPE 123028 presented at the SPE Latin America and Caribbean Petroleum Conference, Catagena, Colombia, 31 May-3 June. doi: 10.2118/123028-MS. 
Ouyang, L.B. and Kikani, J. 2002. Improving Permanent Downhole Gauge (PDG) Data Processing via Wavelet Analysis. Paper SPE 78290 presented at the 13th Europe Petroleum Conference, Aberdeen, Scotland, UK, 29-31 October. doi: 10.2118/78290-MS.

Suzuki, S., \& Chorneyko, D. M. (2009, January 1). Automatic Detection of Pressure-Buildup Intervals From Permanent Downhole Pressure Data Using Filter Convolution. Society of Petroleum Engineers. doi:10.2118/125240-MS

Van Gisbergen, S. J. C. H. M., \& Vandeweijer, A. A. H. (2001, March 1). Reliability Analysis of Permanent Downhole Monitoring Systems. Society of Petroleum Engineers. doi:10.2118/57057-PA 